\title{
Recent Endeavors on Molecular Imaging for Mapping Metals in Biology
}

\author{
Jing Gao' ${ }^{1}$ Yuncong Chen ${ }^{1,2 \bowtie}$, Zijian Guo ${ }^{1,2}$, Weijiang $\mathrm{He}^{1 \bowtie}$ \\ ${ }^{1}$ State Key Laboratory of Coordination Chemistry, School of Chemistry and Chemical Engineering, Nanjing \\ University, Nanjing 210023, China \\ ${ }^{2}$ Chemistry and Biomedicine Innovation Center, Nanjing University, Nanjing 210023, China
}

Received: 2 June 2020 / Accepted: 2 August 2020 / Published online: 4 October 2020

\begin{abstract}
Transition metals such as zinc, copper and iron play vital roles in maintaining physiological functions and homeostasis of living systems. Molecular imaging, including two-photon imaging (TPI), bioluminescence imaging (BLI) and photoacoustic imaging (PAI), could act as non-invasive toolkits for capturing dynamic events in living cells, tissues and whole animals. Herein, we review the recent progress in the development of molecular probes for essential transition metals and their biological applications. We emphasize the contributions of metallostasis to health and disease, and discuss the future research directions about how to harness the great potential of metal sensors.
\end{abstract}

\section{Graphic Abstract}
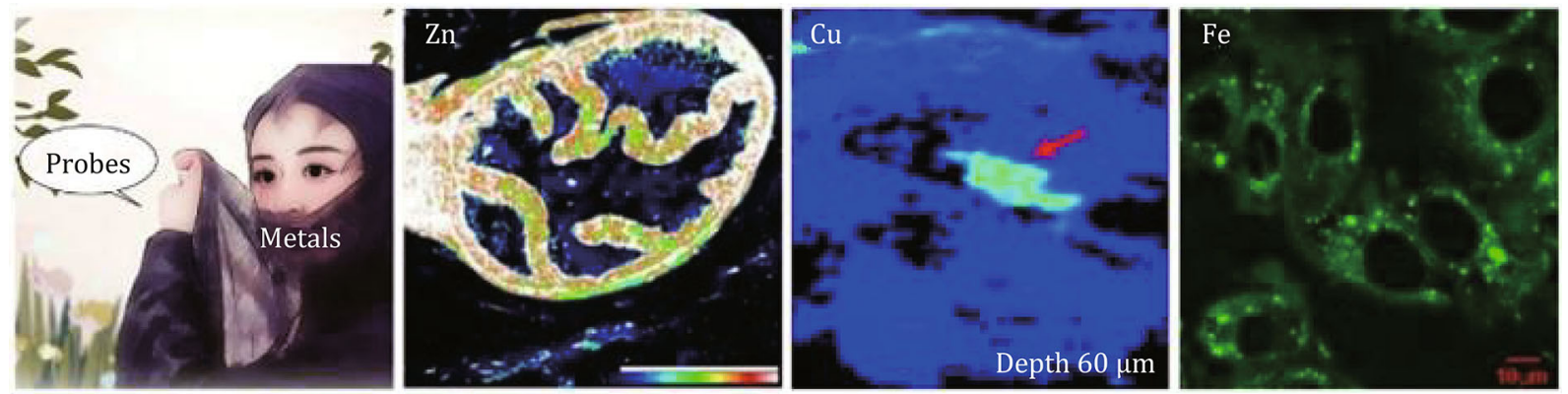

Keywords Molecular imaging, Zinc, Copper, Iron

\section{INTRODUCTION}

Iron, zinc and copper, the top three abundant transition metals in the human body, were well recognized for their essential roles in maintaining homeostasis and sustaining life. There were numerous examples of clinical diseases that were closely associated with metal

$\bowtie$ Correspondence: chenyc@nju.edu.cn (Y. Chen), heweij69@nju.edu.cn (W. He) misregulation, such as Alzheimer's disease (AD), amyotrophic lateral sclerosis (ALS) and Parkinson's disease (PD) (Bleackley and MacGillivray 2011). In this regard, careful maintenance of transition metal homeostasis is required in most living systems.

Labile metal ions, part of the total metal pools, are weakly bound to ligands and can rapidly dissociate (Aron et al. 2015). Redox-active labile metals, such as copper and iron, can be harnessed to create new diagnostics and therapeutics (Chang 2015). Ferrous iron 
$\left(\mathrm{Fe}^{2+}\right)$ is oxidized into ferric iron $\left(\mathrm{Fe}^{3+}\right)$ through reaction with hydrogen peroxide $\left(\mathrm{H}_{2} \mathrm{O}_{2}\right)$, leading to the formation of highly reactive hydroxyl radicals $(\mathrm{OH} \cdot)$, referred to as the Fenton reaction. $\mathrm{Fe}^{3+}$ is reduced back to $\mathrm{Fe}^{2+}$ via reaction with superoxide radicals $\left(\mathrm{O}_{2}{ }^{-}\right)$. This redox cycle is called Harber-Weiss reaction (Hassannia et al. 2019). Like iron, copper $\left(\mathrm{Cu}^{+}\right.$and $\left.\mathrm{Cu}^{2+}\right)$ can transform between two oxidation states under biological conditions. These metals can also undergo kinetically appreciable ligand exchange with sensors that respond to metal binding or reaction with an alteration in signal (light or sound) output (Ackerman et al. 2017).

Fluorescence imaging (FLI) has been widely used in identifying diversified living processes. Providing a potentially non-invasive set of tools with spatial and temporal resolution, molecular imaging drives scientists to peer into biological environments, and unravels the mysteries of metal ions in a sophisticated milieu. Smallmolecule indicators have been assorted into two basic categories for achieving specificity: (1) chelation-based and (2) reaction-based (Ackerman et al. 2017). Fundamental mechanisms such as fluorescence resonance energy transfer (FRET), photoinduced electron transfer (PET) and intramolecular charge transfer (ICT) integrate the foundation for most sensor designs (Chang et al. 2020). Traditional FLI normally utilizes excitation light $<600 \mathrm{~nm}$, which can lead to autofluorescence as well as cell damage, and can be vigorously scattered in deep tissues. To circumvent the high background and low sensitivity, many efforts have been made to develop probes under near infra-red (NIR) light excitation and emission. Accordingly, other imaging modalities such as two-photon imaging (TPI), bioluminescence imaging (BLI) and photoacoustic imaging (PAI) have been developed and attracted much attention. Table 1 points to a contrastive analysis of the three imaging modalities.

Compared with FLI, BLI does not need an excitation light source, resulting in minimized autofluorescence and much higher signal-to-noise ratio (Li et al. 2013). Beetle luciferases oxidize D-luciferin with ATP and $\mathrm{O}_{2}$, generating primarily yellow-green light, whereas marine luciferases release blue photons via the oxidation of imidazopyrazinone analogs (Yao et al. 2018). A growing field of "PAI", which combines optical and ultrasound imaging, shows advantages of high resolution and high contrast at centimeter imaging depths. Theoretically, the design of molecular PAI sensors is primarily based on extending a large $\pi$-conjugated backbone with strong PA signal, for example, porphyrin, boron-dipyrromethene (BODIPY) and cyanine derivatives. Excellent reviews of Chan and coworkers discussing the development of PA agents can be found elsewhere (Knox and Chan 2018; Reinhardt and Chan 2018), and fluorescent sensors for measuring metal ions in living systems are also recommended (Carter et al. 2014; Liu et al. 2013; Park et al. 2020; Trusso Sfrazzetto et al. 2016).

\section{METALLOSTASIS}

\section{Zinc}

In the cellular environment, zinc is redox inert and is present in the +2 oxidation state. As the second-most abundant metals in the human body following iron, $\mathrm{Zn}^{2+}$ is a major cofactor in DNA replication, protein synthesis and cell differentiation (Szewczyk 2013). Some evidence demonstrates that zinc homeostasis in mammals is controlled by the two major families

Table 1 Strengths and weaknesses of representative imaging modalities (Baker 2010)

\begin{tabular}{|c|c|c|c|c|c|c|}
\hline Modality & Labels & Readout & Depth & Resolution & Pros & Cons \\
\hline TPI & $\begin{array}{l}\text { Fluorophores with two- } \\
\text { photon absorption } \\
(700-1100 \mathrm{~nm}) \text { cross } \\
\text { section in GM units }\end{array}$ & Vis-NIR Light & $\sim 1 \mathrm{~mm}$ & $1-2 \mu \mathrm{m}$ & $\begin{array}{l}\text { Less photodamage } \\
\text { and } \\
\text { photobleaching } \\
\text { than the } \\
\text { corresponding FLI }\end{array}$ & $\begin{array}{l}\text { Relatively poor depth } \\
\text { penetration }\end{array}$ \\
\hline BLI & $\begin{array}{l}\text { Bioluminescent enzymes } \\
\text { (typically luciferases) }\end{array}$ & $\begin{array}{l}\text { Light } \\
\quad(500-630 \mathrm{~nm} \\
\text { emission) }\end{array}$ & $\sim 3 \mathrm{~cm}$ & $3-5 \mu \mathrm{m}$ & $\begin{array}{l}\text { No external light, } \\
\text { zero background } \\
\text { emission }\end{array}$ & $\begin{array}{l}\text { Inherently weak emission, } \\
\text { expensive }\left(\sim 3 \times 10^{5}\right. \\
\text { USD) charge-coupled } \\
\text { device (CCD) camera }\end{array}$ \\
\hline PAI & $\begin{array}{l}\text { Probes }\left(\varepsilon>10^{4} /(\mathrm{M} \times\right. \\
\mathrm{cm})) \text { that absorb light } \\
(680-950 \mathrm{~nm}) \text { and } \\
\text { create sound signals }\end{array}$ & Sound & $5-7 \mathrm{~cm}$ & $\sim 50 \mu \mathrm{m}$ & $\begin{array}{l}\text { Better depth than } \\
\text { light }\end{array}$ & $\begin{array}{l}\text { Information processing and } \\
\text { machines still being } \\
\text { optimized }\end{array}$ \\
\hline
\end{tabular}


denoted as ZIP (SLC39A) (Eide 2004) and CDF/ZnT (SLC30A) (Palmiter and Huang 2004).

ZIP transporters confer cytoplasmic $\mathrm{Zn}^{2+}$ uptake (Huang and Tepaamorndech 2013). Zinc is first absorbed from the diet by ZIP4 (Fig. 1), and is delivered to the basolateral membrane or bound to metallothioneins (MTs); the molecular mechanism behind this process has not yet been elucidated (Lazarczyk and Favre 2008; Nishito and Kambe 2018). An excess of unbound cytoplasmic $\mathrm{Zn}^{2+}$ is exported outside cells by ZnTs, predominantly ZnT1, and transported to peripheral tissues. $\mathrm{Zn}^{2+}$ possibly crosses the outer membrane of mitochondria through porin channels, and then bound to MTs in the intermembrane space or further shipped into the mitochondrial matrix via unknown proteins (Lazarczyk and Favre 2008; Nishito and Kambe 2018). Furthermore, a mutual exchange of $\mathrm{Zn}^{2+}$ between the ER and Golgi apparatus through antero- and retrograde vesicular transport has been postulated. $\mathrm{Zn}^{2+}$ is delivered in the opposite direction, from organelles to the cytosol by ZIPs; ZIP1 and ZIP7 (ER and Golgi apparatus) are closely related to this process. The ZIP and ZnT families are highly conserved, and their corresponding genes were found in zebrafish as well. The mRNA level of zinc exporter ZnT1 was upregulated in fish subjected to zinc overload and downregulated through zinc deprivation (Zheng et al. 2008).

\section{Copper}

As the third-most abundant trace metal in the human body, copper not only plays a critical role in physiological processes (Valko et al. 2016), but also associates with cell proliferation and major diseases (Brady et al. 2014). It is revealed that biological functions of copper are essentially dependent on $\mathrm{Cu}^{2+} / \mathrm{Cu}^{+}$transition, also associated with the production of reactive oxidative species (ROS). Abnormal $\mathrm{Cu}^{+} / \mathrm{Cu}^{2+}$ equilibrium can lead to dyshomeostasis, causing many genetic disorders such as Menkes (MNK) disease (Andersson et al. 2014), Wilson disease (WD) (Bandmann et al. 2015), neurodegenerative diseases (Müller et al. 2017) and cancers (Wang et al. 2015).

$\mathrm{Cu}^{2+}$ is reduced to $\mathrm{Cu}^{+}$by an elusive mechanism and can enter cells through copper transporter 1 (CTR1), the principal high-affinity copper importer (Cotruvo et al. 2015). Upon entry, copper interacts with cellular ligands and chaperones that adjust its shipping to

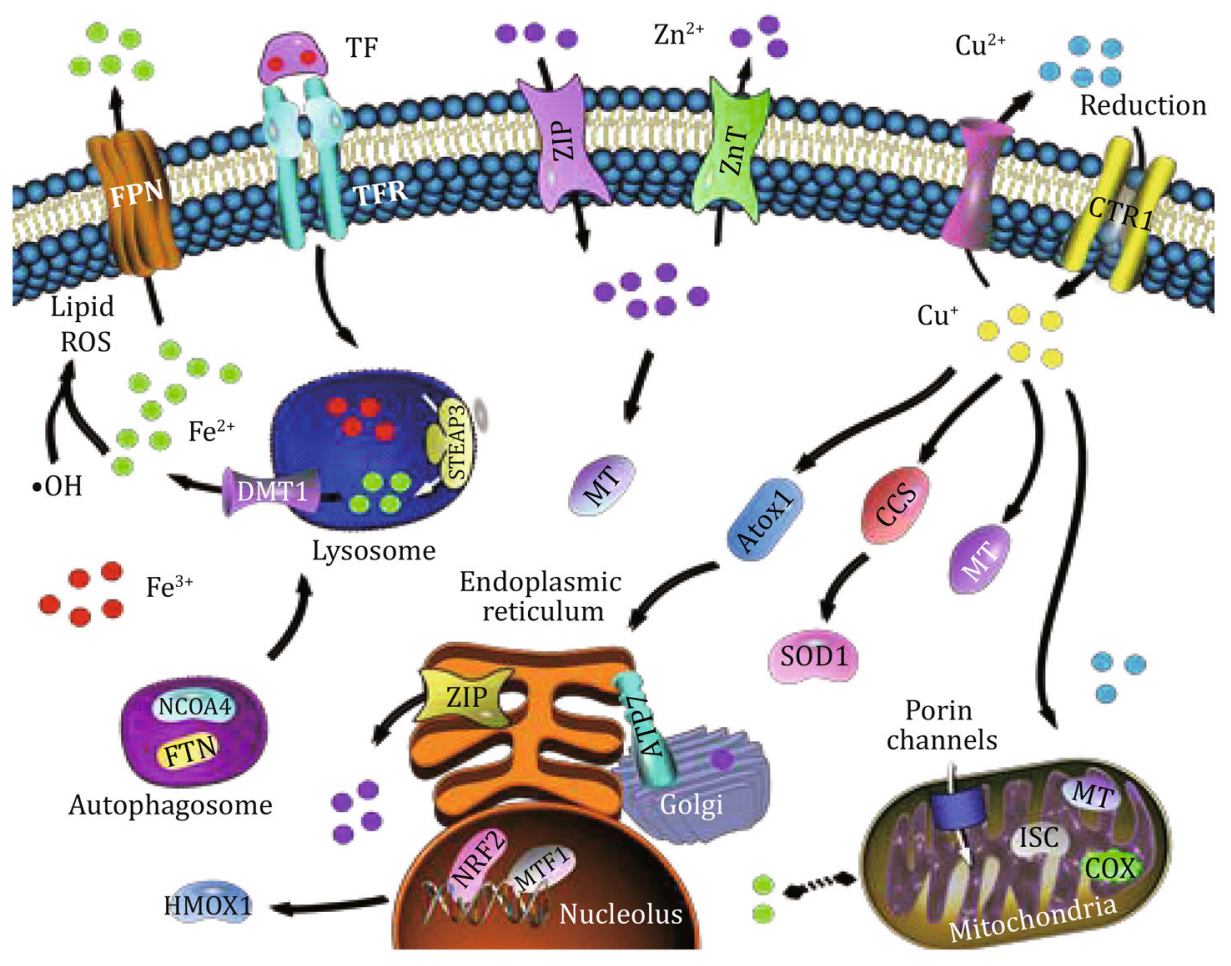

Fig. 1 A simplified overview of zinc, copper and iron handling pathways in mammalian cells. ZIP Zrt/Irt-like protein; ZnT zinc transport protein; CTR1 copper transporter 1; ATOX1 anti-oxidant 1; ATP7 adenosine triphosphatase 7; CCS copper chaperones for superoxide dismutase; SOD1 superoxide dismutase 1; MTF1 metal regulatory transcription factor 1; COX cytochrome c oxidase; MT metallothionein; ISC iron-sulfur cluster; TF transferrin; TFR transferrin receptor; FPN ferroportin; FTN ferritin; NCOA4 nuclear receptor coactivator 4; STEAP3 six-transmembrane epithelial antigen of prostate 3; DMT1 divalent metal transporter 1; NRF2 nuclear factor erythroid 2-related factor 2; HMOX1 heme oxygenase 1 
specific proteins. Glutathione (GSH) can buffer $\mathrm{Cu}^{+}$ pools and mediate $\mathrm{Cu}^{+}$transfer between CTR1 and metallochaperones. Carriage of copper to cytosolic superoxide dismutase 1 (SOD1) proceeds through copper chaperones for superoxide dismutase (CCS). This metallochaperone for $\mathrm{Cu} / \mathrm{Zn} \mathrm{SOD}$ is a known marker for alterations in copper metabolism that inversely correlates with intracellular copper bioavailability (Bertinato et al. 2003; Prohaska et al. 2003). Metal regulatory transcription factor 1 (MTF1) transcriptionally activates MT genes and other targets. Cytosolic copper is delivered to mitochondria for loading onto cytochrome $\mathrm{C}$ oxidase (COX) (Festa and Thiele 2011). Atox1, homolog of Atx1, is responsible for copper delivery to two P-type ATPases, who also participate in copper efflux from cells. They are ATP7A and ATP7B in the trans-Golgi network, where most cuproproteins are metallated. MNK is an X-linked recessive disorder caused by mutations in genes coding for the copper-transport protein ATP7A, leading to copper deficiency. Conversely, $\mathrm{WD}$ is a rare genetic disorder characterized by excess copper stored in various body tissues (Bansagi et al. 2016).

\section{Iron}

As the most abundant transition metal in the human body, iron is essential and required for a variety of physiological and pathological processes (Theil and Goss 2009). Iron deficiency anemia (IDA) is imposed by a lack of iron, whereas hereditary hemochromatosis $(\mathrm{HH})$ is an iron-overload disorder (Andrews 2000). Once iron is put into circulation, it is first bound to transferrin (TF) as $\mathrm{Fe}^{3+}$ and can subsequently enter cells, which maintain iron homeostasis through a balance of import proteins including transferrin receptor (TFR), divalent metal transporter 1 (DMT1), storage proteins like ferritin (FTN), and export proteins like ferroportin (FPN) (Aron et al. 2018). It is worth noting that metalloreductase STEAP3 (six-transmembrane epithelial antigen of prostate 3) converts $\mathrm{Fe}^{3+}$ to $\mathrm{Fe}^{2+}$. In mitochondria, iron-sulfur (Fe/S) cluster proteins (ISCs) are generated from iron and cysteine and are indispensable cofactors for proteins in mitochondrial respiration and other cellular activities (Braymer and Lill 2017).

Aberrant iron levels are implicated in ailments such as pyroptosis and ferroptosis (Zhou et al. 2018). Ferroptosis is a newly recognized cell death modality marked by the oxidative modification of phospholipid membranes via an iron-dependent mechanism and that has drawn constantly increasing attention in chemical biology (Conrad et al. 2016; Friedmann Angeli et al.
2019). Augmented levels of nuclear factor erythroid 2-related factor 2 (NRF2) protein after treatment with erastin and sorafenib (inducers of ferroptosis) render cells resistant to ferroptosis. This protection is traced to upregulation of NRF2 target genes like heme oxygenase 1 (HMOX1). Lysosomes can accumulate a large quantity of iron through degradation of FTN (coined ferritinophagy). Inhibition of lysosomal activity or silencing of nuclear receptor coactivator 4 (NCOA4), a cargo receptor recruiting FTN to autophagosomes for lysosomal degradation and iron release, suppresses ferroptosis (Hassannia et al. 2019). Remarkably, a novel quinolone-derived fluorescent turn-on probe IQ44 has been enabling the visualization of autophagosomelysosome fusion in the process of autophagy (Lim et al. 2019).

\section{MOLECULAR IMAGING}

\section{Zinc}

Our laboratory reported a turn-on $\mathrm{Zn}^{2+}$ sensor NBDTPEA, the first example for monitoring zinc ions in neuromasts of zebrafish via fluorescence (Qian et al. 2009). By replacing $-\mathrm{NO}_{2}$ moiety with $-\mathrm{SO}_{2} \mathrm{NH}_{2}$, we devised an ICT ratiometric fluorescent probe, SBD-TPEA, for $\mathrm{Zn}^{2+}$ imaging in biological systems (Liu et al. 2014). In the presence of $\mathrm{Zn}^{2+}(50 \mathrm{mmol} / \mathrm{L}$ HEPES/DMSO = 99.85/0.15, pH 7.2), SBD-TPEA exhibits an emission band centered at $585 \mathrm{~nm}$, with an excitation maximum at $466 \mathrm{~nm}$. However, addition of $\mathrm{Zn}^{2+}$ to the probe leads to a distinct hypsochromic emission shift from 585 to $545 \mathrm{~nm}$ with a well-defined isoemission point at $585 \mathrm{~nm}$. This change is attributed to ICT alteration when $\mathrm{Zn}^{2+}$ binds to the probe. The dissociation constant $\left(K_{\mathrm{d}}\right)$ of the SBD-TPEA $/ \mathrm{Zn}^{2+}$ complex was estimated to be $2.1 \mathrm{nmol} / \mathrm{L}$ and its limit of detection (LOD) for $\mathrm{Zn}^{2+}$ was $0.5 \mathrm{nmol} / \mathrm{L}$. Because SBD-TPEA responded selectively to $\mathrm{Zn}^{2+}$ without interference from other metal ions, it was utilized to image $\mathrm{Zn}^{2+}$ in HepG2 cells and zebrafish larvae (Fig. 2).

Through integrating a $\mathrm{Zn}^{2+}$ ionophore N,N'-bis(pyridin-2-ylmethyl)ethane-1,2-diamine (BPEA) as the ICT donor of the ANaph fluorophore, we constructed NaphBPEA with nuclear envelope penetrability (Zhang et al. 2013). Of note, this probe did not merely localize in the cell nucleus, it also fluoresced in the cytoplasm. More importantly, our group summarized photoluminescence $\mathrm{Zn}^{2+}$ imaging in living subjects before 2015 (Chen et al. 2015). Apart from biological functions and sensing mechanisms of labile $\mathrm{Zn}^{2+}, \mathrm{Zn}^{2+}$ roles within an array of subcellular compartments, such as mitochondria, 

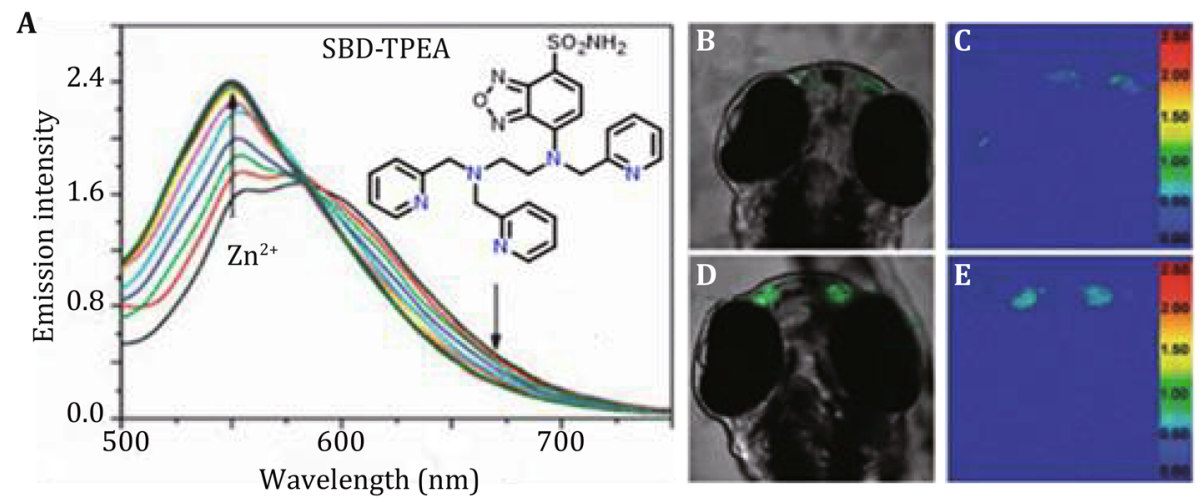

Fig. 2 A Emission spectra of $3 \mathrm{mmol} / \mathrm{L}$ SBD-TPEA $\left(\lambda_{\mathrm{ex}}=460 \mathrm{~nm}\right.$ ) in buffer (50 mmol/L HEPES/DMSO = 99.85/0.15, pH 7.2) obtained by adding aliquots of $\mathrm{Zn}^{2+}$ solution $(1.2 \mathrm{mmol} / \mathrm{L})$; Inset in A: chemical structure of SBD-TPEA. B-E Confocal fluorescence ratiometric $\mathrm{Zn}^{2+}$ imaging in the head of a 3-day-old zebrafish larva stained with SBD-TPEA. B Overlay of bright field and fluorescence image of the SBD-TPEA-stained zebrafish larva from the green channel. C Ratiometric image based on the fluorescence images of the zebrafish larva in B. D Overlay of bright field and fluorescence image of the SBD-TPEA-stained zebrafish larva from the green channel after feeding the larva with $\mathrm{Zn}^{2+}$ solution (100 mmol/L) for $1 \mathrm{~h}$. E Ratiometric image of the larva in D. Green channel images obtained with a bandpath of 510-560 nm, and red channel images obtained with a bandpath of 580-630 nm upon excitation at $488 \mathrm{~nm}$. Adapted from Liu et al. (2014)

lysosome, endoplasmic reticulum (ER), and Golgi apparatus were illuminated in detail, with corresponding $\mathrm{Zn}^{2+}$ sensors displayed. Localization is usually defined by comparing the colocalization of the sensor with a well-established organelle marker and quantifying the overlap using Pearson's correlation coefficient (PCC) given by a imaging software (Carter et al. 2014). Organelle-specific $\mathrm{Zn}^{2+}$ probes have been developed to study $\mathrm{Zn}^{2+}$ distribution in different subcellular compartments (Fig. 3); we will only introduce some representative works due to limited space of this review; readers are encouraged to refer to another review for more detailed information (Zhu et al. 2016).

\section{Golgi-Targeting}

Golgi apparatus contain various metalloproteases and alkaline phosphatases, whose catalytic activities rely largely on the $\mathrm{Zn}^{2+}$ ions. In 2015, the Kim research group reported a Golgi-localized two-photon ratiometric probe for zinc ions (Singh et al. 2015). The dipicolylamine moiety within the compound SZnC selectively makes a complex with $\mathrm{Zn}^{2+}(30 \mathrm{mmol} / \mathrm{L} \mathrm{MOP} / \mathrm{EtOH}=$<smiles>COc1cc(NC(=O)CN(C)c2ccc3cc(-c4nc5ccc(C(=O)O)cc5s4)ccc3c2)ccc1NCCN(Cc1ccccn1)Cc1ccccn1</smiles><smiles>CCNCCCCN1C(=O)C2=C(c3ccccc3)N(CC(=O)Nc3ccc(NCCN(Cc4ccccn4)Cc4ccccn4)c(OC)c3)C(=O)C2=C1c1ccccc1</smiles>

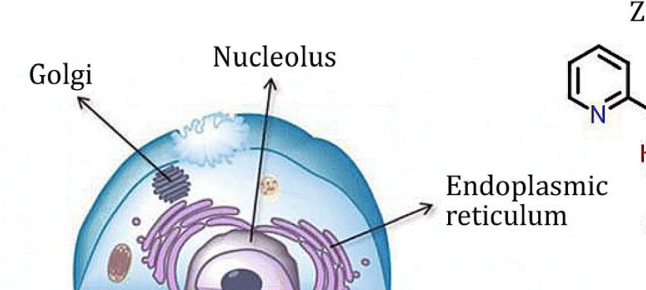<smiles>O=c1c(Cl)cc2nc3cc(Cl)c(O)c(CN(Cc4ccccn4)Cc4ccc[nH]4)c3oc-2c1CN(Cc1ccccn1)Cc1ccccn1</smiles>

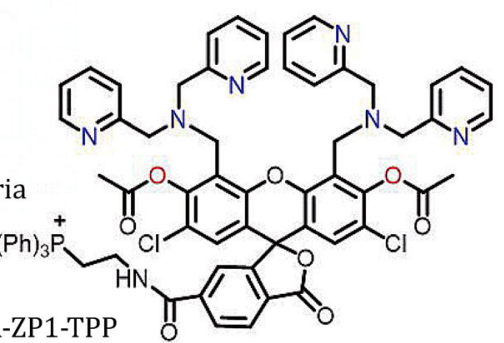

Fig. 3 Organelle-specific reversible $\mathrm{Zn}^{2+}$ probes. Golgi-targeting SZnC, ER-targeting ZR1, mitochondria-targeting DA-ZP1-TPP and lysosome-targeting LysoDPP-C4. Adapted from Zhu et al. (2016) 
1:1, pH 7.2), with an emission enhancement peaked at $500 \mathrm{~nm}$. The TP action cross-section values $\left(\Phi_{\delta \max }\right)$ of SZnC in the absence and presence of excess $\mathrm{Zn}^{2+}$ were determined to be 16 and $92 \mathrm{GM}$, while the fluorescence quantum yield $\Phi$ were 0.12 and 0.93 , respectively. Featuring low cytotoxicity and high photostability, this probe can be leveraged to monitor $\mathrm{Zn}^{2+}$ fluctuations in real time and getting a 3D distribution picture in the Golgi apparatus.

\section{ER-Targeting}

Metal ions, such as $\mathrm{Cu}^{+}$and $\mathrm{Zn}^{2+}$, are required for ER functions. Recently, Lippard and coworkers synthesized a new red-emitting fluorescent probe ZR1 to monitor mobile $\mathrm{Zn}^{2+}$ in the ER, a benzoresorufin fluorophore functionalized with two 2,2'-dipicolylamine (DPA) arms (Loas et al. 2014). The free probe was non-fluorescent ( $50 \mathrm{mmol} / \mathrm{L}$ PIPES, pH 7.0) due to PET from the $\mathrm{Zn}^{2+}$ chelators, while $\mathrm{Zn}^{2+}$-binding strongly elevated its emission maximum at $611 \mathrm{~nm}$ and an $18 \mathrm{~nm}$ Stokes shift. On average, the associated brightness values $(\varepsilon \Phi)$ enhanced 44 -fold to $2.43 \times 10^{4}(\mathrm{~L} /(\mathrm{mol} \cdot \mathrm{cm}))$. In comparison with ZBR4, which anchors to the mitochondria, ZR1 spontaneously localizes to the endoplasmic reticulum of HeLa cells.

\section{Mitochondria-Targeting}

Using fluorescein fluorophore instead, Lippard and coworkers presented a reaction-based fluorescent sensor DA-ZP1-TPP, which selectively localized at the mitochondria (Chyan et al. 2014). Coordination of $\mathrm{Zn}^{2+}$ enhances fluorescence intensity by promoting ester hydrolysis and alleviating PET origination from the DPA motif. Adding nanomolar concentrations of free zinc ions resulted in large increases in both the absorption $\left(\lambda_{\mathrm{abs}}=510 \mathrm{~nm}\right)$ and fluorescence $\left(\lambda_{\mathrm{em}}=529 \mathrm{~nm}\right)$ spectral bands of DA-ZP1-TPP (50 mmol/L PIPES, pH 7.0). These optical changes combined to yield a $>140$ fold increase in the fluorescence signal $\left(\Phi_{\mathrm{Zn}}=0.75\right)$. With this probe, it is concluded that tumorigenic cancer cells lose the ability to accumulate $\mathrm{Zn}^{2+}$ within their mitochondria in contrast to healthy epithelial prostate cells.

Indeed, close correlations between prostatic $\mathrm{Zn}^{2+}$ levels and prostate cancer ( $\mathrm{PCa}$ ) have been reported (Costello et al. 2004). At least three ZIPs and six ZnTs are expressed in a lobe-dependent manner in the prostate (Kelleher et al. 2011). In malignant prostate tissues, there is a dramatic decline in $\mathrm{Zn}^{2+}$ concentration $(500 \mathrm{nmol} / \mathrm{g}$ vs. $3000 \mathrm{nmol} / \mathrm{g}$ for cancerous and healthy tissues, respectively), as well as a downregulation of ZIP1 (Kolenko et al. 2013).

\section{Lysosome-Targeting}

Very recently, LysoDPP-C4 has been developed for the evaluation of low $\mathrm{pH}$ and $\mathrm{Zn}^{2+}$ in an AND logic fashion to investigate lysosomal $\mathrm{Zn}^{2+}$ in prostate cancer cells (Du et al. 2019). A morpholine unit is appended for targeting lysosomes, as confirmed by HeLa cell fluorescence imaging studies. LysoDPP-C4 demonstrated an excellent selectivity toward $\mathrm{Zn}^{2+}$ and the resulting LysoDPP-C4/ $\mathrm{Zn}^{2+}$ complexes proved insensitive to $\mathrm{pH}$ 3.5-9. At low $\mathrm{pH}, \mathrm{Zn}^{2+}$ chelation contributes to a large increase in the fluorescence intensity at $515 \mathrm{~nm}\left(\lambda_{\mathrm{ex}}\right.$ $=430 \mathrm{~nm}$ ) ascribed to suppression of PET. The sensor formed a host-guest complex in 1:1 stoichiometry with $K_{\mathrm{d}}=1.91 \mathrm{nmol} / \mathrm{L}$. Besides, histological studies using a human sample revealed that LysoDPP-C4 could distinguish between cancerous prostate tissue and healthy one.

In view of the advances in $\mathrm{Zn}^{2+}$-specific chelators (TPEA, BPEA, DPA, etc.) and $\mathrm{Zn}^{2+}$-complexation-induced spirolactam ring-opening or hydrolysis (Jin et al. 2018), concurrent with phosphorescence lifetime imaging (PLIM) of labile $\mathrm{Zn}^{2+}$ (Zhang et al. 2018), it is not surprising that $\mathrm{Zn}^{2+}$ sensors constitute the largest family of fluorescent indicators for transition metals. Some of them are reversible and ratiometric, applied to appealing models. So far, the physiological participation of this ion is not completely clear in spite of the large arsenal of fluorescent $\mathrm{Zn}^{2+}$ sensors.

\section{Copper}

Molecular sensors are intriguing tools to visualize the distribution and speciation of labile copper. Nevertheless, there are added challenges posed by aiming at labile copper over $\mathrm{Zn}^{2+}$ due to the need for discrimination between different oxidation states, the quenching nature of $\mathrm{Cu}^{2+}$, and the fact that probes must have enough affinities to compete for copper within its biological window $\left(10^{-21}-10^{-17} \mathrm{M}\right.$ ) (Wegner et al. 2011). In consequence, only a fraction of copper sensors has been utilized for biologically accessible copper. The Kim group shed light on the pathophysiological part of copper ions and sensors for the measurement thereof (Peter et al. 2015).

$\mathrm{Cu}^{+}$

Although $\mathrm{Cu}^{+}$is prone to disproportionation and acquires stabilization by specific ligands in aqueous 
media (Paredes and Das 2011), it is considered to be the dominant intracellular copper oxidation state of labile copper pools (Festa and Thiele 2011). Most of the probes designed for biological systems target $\mathrm{Cu}^{+}$ engaged in two common aspects as follows (Fig. 4).

(A) $\mathrm{NS}_{4}$-based chelation.

Thioether $\left(\mathrm{NS}_{4}\right)$ receptors can be modified to develop fluorescent $\mathrm{Cu}^{+}$sensors. One notable example is CTAP1, the first small-molecule sensor for mapping labile $\mathrm{Cu}^{+}$in cells (Yang et al. 2005). Soon after this study, the Chang group presented coppersensor 1 (CS1) with visible excitation and emission profiles (Zeng et al. 2006). Tuning the BODIPY fluorophore of CS1 to a rhodol scaffold produced a more hydrophilic $\mathrm{Cu}^{+}$sensor called copper Fluor-3 (CF3) (Dodani et al. 2014). As described earlier, fluorescent sensors that excited at short wavelengths succumb to limited penetration depths, high autofluorescence and inevitably induce photobleaching and photodamage. These flaws hinder their use for longterm imaging in tissues and organisms. One way to remove these limitations is by NIR single-photon excitation (Guo et al. 2014). Cao $\mathrm{Cu}-3$ represents a novel NIR fluorescent turn-on probe suitable for imaging endogenous $\mathrm{Cu}^{+}$ions in living systems (Cao et al. 2012).

Another approach is to use two-photon microscopy (TPM), employing NIR photons of lower energy as the excitation source to possess the advantage of deepened penetration $(>500 \mu \mathrm{m})($ Kim et al. 2014). Our laboratory presented the first-generation ER-localized TP $\mathrm{Cu}^{+}$ sensor CNSB (Guo et al. 2019). There is a distinct overlap between coumarin-A (donor) emission and 4-amino-7-sulfamoyl benzoxadiazole (ASBD, acceptor) absorption, implying these two compounds are qualified candidates as a FRET pair to compose ratiometric sensors. CNSB exhibits $\sim 7.44 \times 10^{-11} \mathrm{M} \quad K_{\mathrm{d}}$ value $(10 \mathrm{mmol} / \mathrm{L}$ Tris-HCl$/ \mathrm{DMF}=6: 4, \mathrm{pH} 7.2)$ and the $\mathrm{Cu}^{+}$enhanced emission ratio $\mathrm{F}_{470} / \mathrm{F}_{565}$ is stable from $\mathrm{pH} 4.0$ to 8.0. The sensor was applied to assessing $\mathrm{Cu}^{+}$fluctuation in MCF-7 cells pre-incubated with tunicamycin, proving the relationship between $\mathrm{Cu}^{+}$augmentation and ER stress. Meanwhile, the spatial distribution of $\mathrm{Cu}^{+}$in the heart slice of a 2-week rat was observed via TPI owing to the two-photon ability of coumarin fluorophore. Negligible enhancement of coumarin emission was observed during the fluorescent titration of CNSB.

(B) $\mathrm{O}_{2}$-dependent $\mathrm{C}-\mathrm{O}$ bond cleavage.

Inspired by the $\mathrm{O}_{2}$ activation for copper-dependent enzymes, the Chang group adapted the $\mathrm{Cu}^{+}$chelator tris(2-pyridylmethyl)amine (TPA) to develop coppercaged luciferin-1 (CCL-1) (Heffern et al. 2016), a bioluminescent reporter for monitoring labile $\mathrm{Cu}^{+}$levels in a diet-induced mouse model of non-alcoholic fatty liver disease (NAFLD) that manifests as a hepatic copper deficiency, revealing altered expression levels of central copper trafficking proteins that accompany symptoms of glucose intolerance and weight gain (Fig. 5). As supported by Western blot, CCS levels were elevated in the high-fat diet (HFD) mice over control diet mice, and the major copper exporter proteins ATP7A and ATP7B were also upregulated.

Not long ago, linking fluorescein donor and rhodamine acceptor through the TPA bridge, they reported reaction-based ratiometric FRET copper probe FCP-1. Together with its 2 -color response $\left(\mathrm{F}_{526} / \mathrm{F}_{576}\right)$, collective results indicate that oncogene-driven changes in the metabolism of GSH, a major cellular redox buffer, leads to a labile $\mathrm{Cu}^{+}$deficiency with differential expression of CTR1 (Chung et al. 2019). This work connects $\mathrm{Cu}^{+}$ dysregulation and GSH stress in cancer, providing a roadmap for studying the crosstalk between metal and redox pathways in physiology and pathology with probes.

$\mathrm{Cu}^{2+}$

As synthetic fluorescent probes for monovalent copper have been thoroughly reviewed by others (Cotruvo et al. 2015; Fahrni 2013), we focus our discussion on $\mathrm{Cu}^{2+}$
Fig. 4 Design approaches and selected structures for $\mathrm{Cu}^{+}$ detection. $\mathbf{A ~ N S}$-based chelation: $\mathrm{CNSB} . \mathrm{O}_{2}$-dependent $\mathrm{C}-\mathrm{O}$ bond cleavage: CCL-1
A

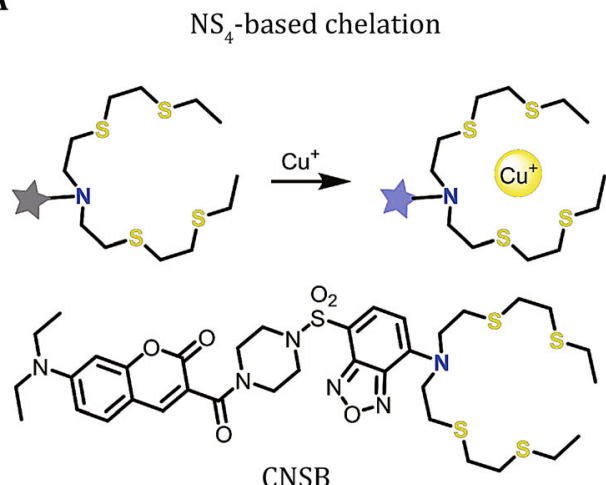

B

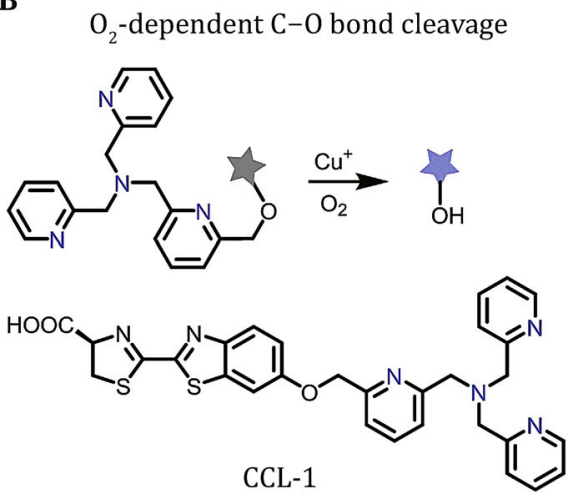


A

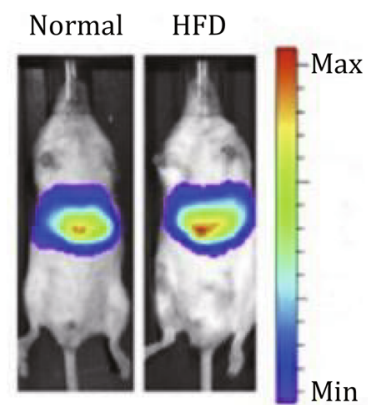

Day 0

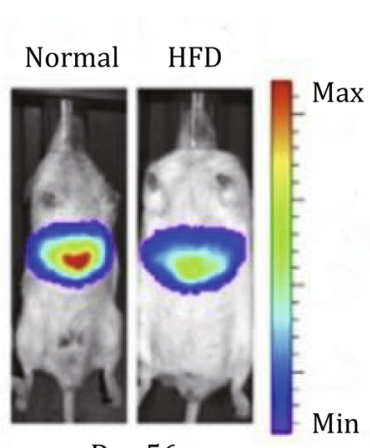

Day 56

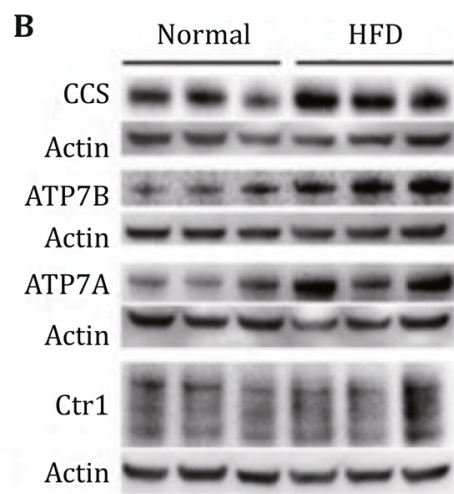

Fig. 5 CCL-1 imaging reveals hepatic copper deficiency in a diet-induced murine model of NAFLD. A Representative images of mice from HFD and normal diet groups before the study (day 0) and at the end of the 8-week feeding period (day 56). B Western blot analysis of liver extracts of three mice fed normal diets and three HFD mice. Adapted from Heffern et al. (2016)

probes that compensate for these areas of copper sensing. A large library of luminescent chemodosimeters for $\mathrm{Cu}^{2+}$ bioimaging has been collected by Fuyou Li et al. (Yang et al. 2013). Most of such probes recognize $\mathrm{Cu}^{2+}$ by three principal categories: chelation, hydrolysis and oxidation (Fig. 6). Among them, the oxidation pattern draws in the fewest probes while the other two seem more attractive.

Chelation As mentioned previously, 2,2'-dipicolylamine (DPA) can be manipulated to design probes selective for $\mathrm{Cu}^{2+}$ over $\mathrm{Zn}^{2+}$ (Ballesteros et al. 2009). Modifying the FRET pair of CNSB with DPA unit forms a reversible ratiometric sensor CSBPA for intracellular $\mathrm{Cu}^{2+}$ imaging (Chen et al. 2013). Later we achieved in vivo fluorescence imaging for $\mathrm{Cu}^{2+}$ in live mice for the first time by a BODIPY-derived NIR fluorescent sensor

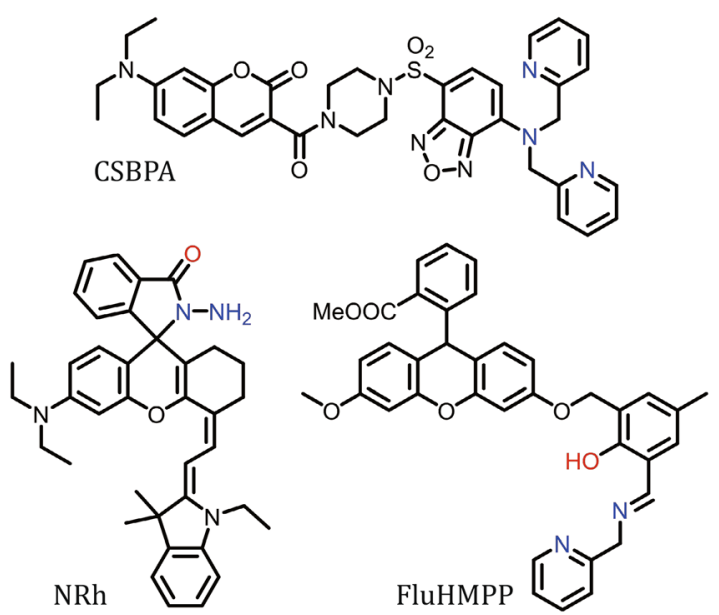

Fig. 6 Selected structures of $\mathrm{Cu}^{2+}$-responsive probes based on chelation: CSBPA (A), hydrolysis: NRh (B) and oxidation: FluHMPP (C)
BDPA (Xue et al. 2016), profiting from its large Stokes shift $(\sim 100 \mathrm{~nm})$, excellent photostability and high quantum yield $(\Phi=0.85)$.

Wang et al. developed a series of activatable PA probes with low molecular weights $(<438 \mathrm{Da})$, and could specifically chelate with $\mathrm{Cu}^{2+}$ to form radicals displaying turn-on PA signals in the NIR region (Wang et al. 2019a). Introducing the electron-donating group $\mathrm{N}, \mathrm{N}$-dimethylaniline into the probe was found to significantly enhance the radical stability and PA intensity. The best probe in the series, RPS1, produced a fast response (within seconds) to $\mathrm{Cu}^{2+}$ with a low LOD of $90.9 \mathrm{nmol} / \mathrm{L}(0.02 \mathrm{~mol} / \mathrm{L} \mathrm{PBS}, \mathrm{pH}$ 7.4). Owing to the low molecular weight and amphiphilic structure, RPS1 could effectively cross the blood-brain barrier (BBB) and thus maps $\mathrm{Cu}^{2+}$ in the brains of AD mice via PAI for the first time (Fig. 7).

Hydrolysis The group headed by Chan reported the synthesis and photoacoustic properties of APC-1 and APC-2, two ratiometric probes for mobile $\mathrm{Cu}^{2+}$ ( $\mathrm{Li}$ et al. 2015). Upon binding $\mathrm{Cu}^{2+}$, the sensors display 89- and 101-fold enhancements of normalized ratiometric turnon responses, respectively. Both APCs are equipped with a 2-picolinic ester sensing module that is readily hydrolyzed in the presence of $\mathrm{Cu}^{2+}$ but not by other divalent metal ions. Additionally, ratiometric PAI was realized by using an aza-BODIPY dye scaffold exhibiting two spectrally resolved NIR absorbance bands, which correspond to the 2-picolinic ester capped and uncapped phenoxide forms.

Combining $\mathrm{Cu}^{2+}$-promoted hydrolysis with spirolactam ring-opening generates an effective strategy to construct fluorescent $\mathrm{Cu}^{2+}$ chemodosimeters. A ratiometric TP probe for $\mathrm{Cu}^{2+}$ trafficking based on through- 

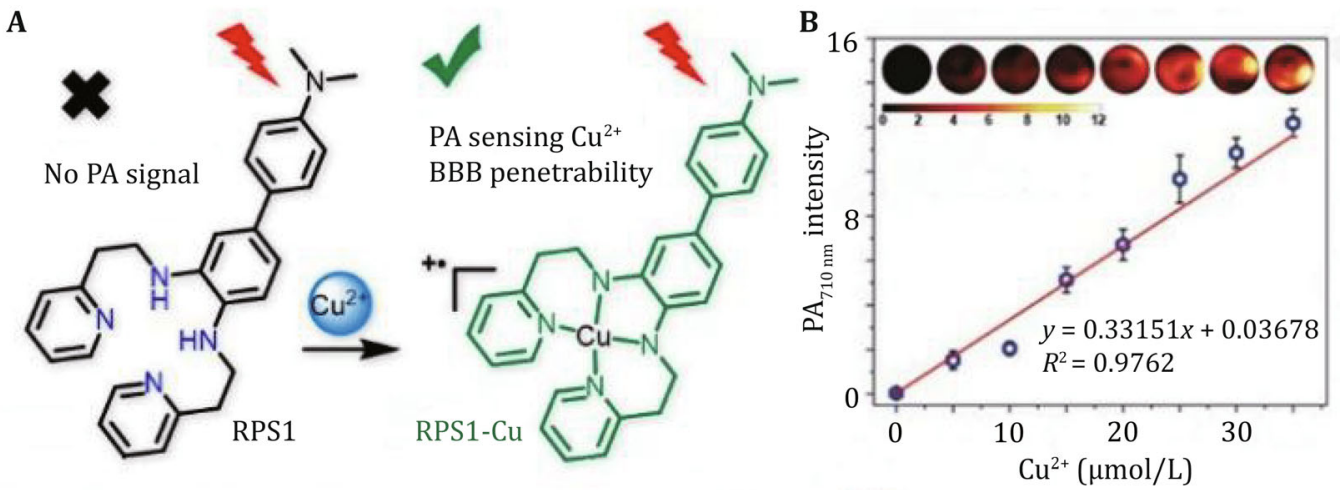

C

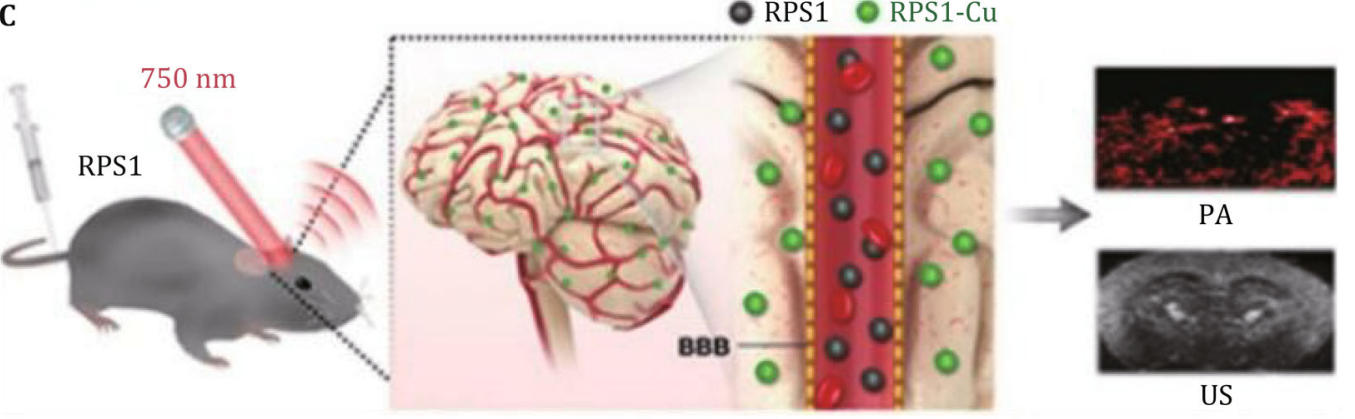

Fig. 7 A Experimental design of target PA probe RPS1 for $\mathrm{Cu}^{2+}$ analysis. B Calibration curve of the PA intensity at $710 \mathrm{~nm}$ for measuring $\mathrm{Cu}^{2+}$ in the range of $0-35 \mu \mathrm{mol} / \mathrm{L}$. C Schematic diagram of RPS1 crossing the BBB and detecting $\mathrm{Cu}^{2+}$, as observed by PAI. Adapted from Wang et al. (2019a)

bond energy transfer (TBET) was designed by directly conjugating BODAN (donor, green emission) and rhodamine spirolactam (acceptor, red emission) (Fig. 8)

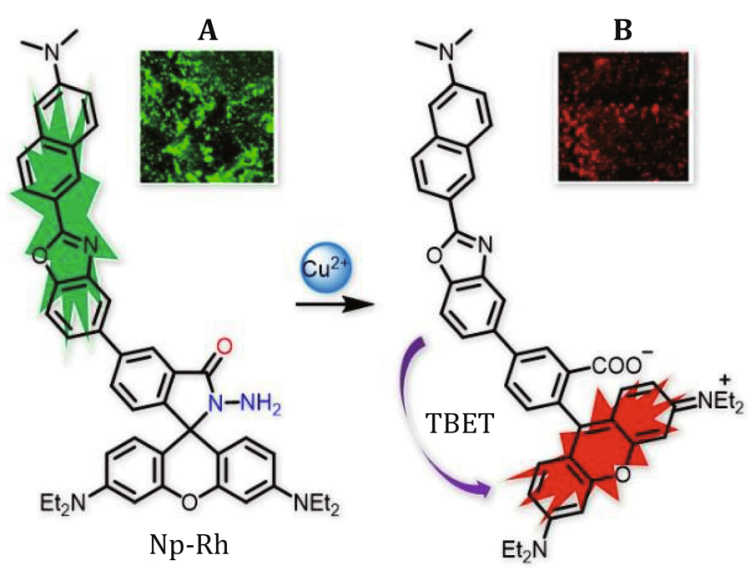

Fig. 8 Two-photon TBET probe Np-Rh. TPI of a rat liver frozen slice stained with $10 \mu \mathrm{mol} / \mathrm{L} \mathrm{Np}-\mathrm{Rh}$ at $\sim 95 \mu \mathrm{m}$ for $60 \mathrm{~min}$ (A), followed by treatment with $100 \mu \mathrm{mol} / \mathrm{L} \mathrm{Cu}^{2+}$ and incubated for another $60 \mathrm{~min}$ (B). Green channel images obtained with a bandpath of 450-530 $\mathrm{nm}$ (A), and red channel images obtained with a bandpath of 540-650 $\mathrm{nm}$ upon excitation at $780 \mathrm{~nm}$ with femtosecond pulses (B). Adapted from Zhou et al. (2014)
(Zhou et al. 2014). Np-Rh elicits a ratiometric response $\left(\mathrm{EtOH} / \mathrm{H}_{2} \mathrm{O}=1: 9\right)$ upon addition of $\mathrm{Cu}^{2+}$, with highly efficient energy transfer (93.7\%) and two well-resolved emission peaks separated by $100 \mathrm{~nm}$. Moreover, the $\mathrm{Cu}^{2+}$ distribution in Np-Rh-labeled HeLa cells as well as rat liver frozen slices pretreated with $\mathrm{Cu}^{2+}$ was visualized using TPM in the $450-530$ and $540-650 \mathrm{~nm}$ collection windows.

Similarly, Fuyou Li and coworkers introduced a frequency upconversion luminescence (UCL) $\mathrm{Cu}^{2+}$ chemodosimeter $\mathrm{NRh}$ (Liu et al. 2016), lighting up efficient single-photon upconversion emission at $730 \mathrm{~nm}$ under NIR excitation at $808 \mathrm{~nm}$. This probe can serve as an ideal $\mathrm{Cu}^{2+}$ sensor for ex vivo and in vivo assay in a WD mouse model. Impressively, the exploitation of UCL small-molecule probes and their bioimaging applications have been attracting much attention (Dong et al. 2018; Yang et al. 2016; Zhang et al. 2017).

Oxidation Subsequently, the same group developed an easy-to-use probe CYDA based on UV-vis-NIR absorption changes with excellent sensitivity and selectivity for $\mathrm{Cu}^{2+}$ (Shi et al. 2018). The mechanism of CYDA oxidation by $\mathrm{Cu}^{2+}$ was first explored (Fig. 9). In aqueous solution $\left(\mathrm{EtOH} / \mathrm{H}_{2} \mathrm{O}=1: 1\right)$, addition of $\mathrm{Cu}^{2+}$ to $\mathrm{CYDA}$ 

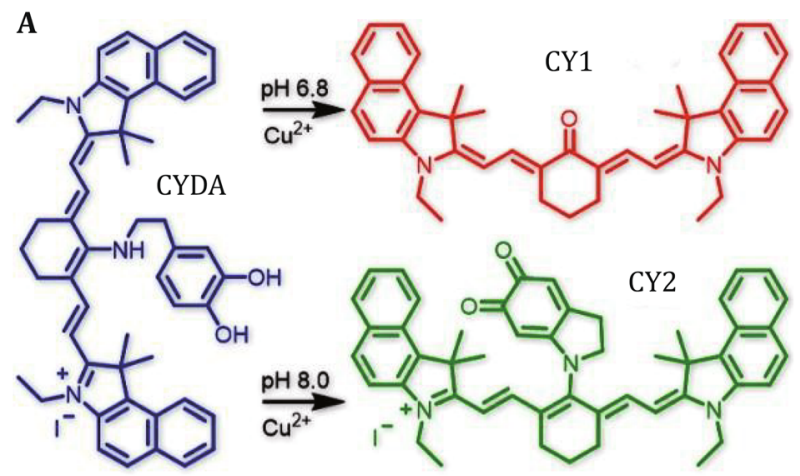

B
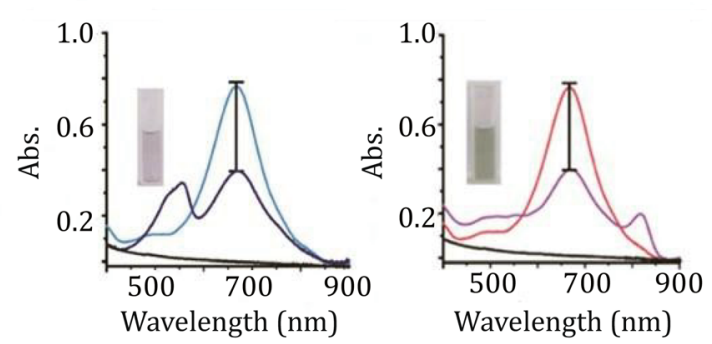

Fig. 9 A Oxidation of CYDA by $\mathrm{Cu}^{2+}$ in acidic solution ( $\mathrm{pH}$ 6.8) and alkaline solution $(\mathrm{pH}$ 8.0), respectively. B UV-Vis-NIR absorption spectra (WD patients' urine/EtOH/HEPES $=10: 10: 1$ ) of $10 \mu \mathrm{mol} / \mathrm{L} \mathrm{CYDA}$ when the $\mathrm{pH}$ value was 6.8 (left), 8.0 (right), from top to bottom: CYDA/Urine ${ }_{\text {start }}$ CYDA/Urine $_{\text {end }}$ and Urine. Adapted from Shi et al. (2018)

induced significant changes in the absorption spectra. When the solution was mildly acidic ( $\mathrm{pH}$ 6.8), the absorbance at $670 \mathrm{~nm}$ went down, with the absorbance at $553 \mathrm{~nm}\left(\varepsilon=1.09 \times 10^{5} \mathrm{~L} /(\mathrm{mol} / \mathrm{cm})\right)$ up, accompanied by the solution color changes from blue to red. In alkaline solutions ( $\mathrm{pH} \mathrm{8.0),} \mathrm{the} \mathrm{absorbance} \mathrm{at} 670 \mathrm{~nm}$ $\left(\varepsilon=2.14 \times 10^{5} \mathrm{~L} /(\mathrm{mol} / \mathrm{cm})\right)$ dropped gradually, whereas the absorbance at $823 \mathrm{~nm}\left(\varepsilon=0.22 \times 10^{5} \mathrm{~L} /\right.$ $(\mathrm{mol} / \mathrm{cm}))$ rose with an isosbestic point at $\lambda=793 \mathrm{~nm}$. In the meantime, the solution color tuned into grayish blue. These phenomena confirmed the formation of CY1 and CY2. They further demonstrated that the probe was able to quantify $\mathrm{Cu}^{2+}$ in urine from WD patients.

Even a bit earlier than the above study, oxidative $\mathrm{C}-\mathrm{O}$ bond cleavage turn-on probe FluHMPP has been prepared (Shi et al. 2013). On addition of 20 equiv of $\mathrm{Cu}\left(\mathrm{NO}_{3}\right)_{2}\left(10 \mathrm{mmol} / \mathrm{L}\right.$ Tris- $\left.\mathrm{HCl} / \mathrm{CH}_{3} \mathrm{CN}=7: 3, \mathrm{pH} 7.2\right)$, there was a strong emission enhancement (30-fold) after $2 \mathrm{~h}$. Confocal microscopy experiments have demonstrated that FluHMPP was membrane permeable and capable of tracing exogenous $\mathrm{CuCl}_{2}$ in HeLa cells. Nevertheless, such $\mathrm{C}=\mathrm{N}$ structures are unstable and sensitive to reactive oxygen species.
Iron

Despite great interest in labile iron pool (LIP), its biological function remains insufficiently understood, in part due to a relative lack of tools for directly assessing labile iron in living specimens (Dixon and Stockwell 2014). Molecular imaging using iron selective sensors opens up a broad avenue for better understanding the complex handling of iron in biology. Ideally, probes should be able to track biological iron status, selectively detecting either $\mathrm{Fe}^{2+}$ or $\mathrm{Fe}^{3+}$ or responding to iron species such as heme-iron or ISCs. Because $\mathrm{Fe}^{2+}$ and $\mathrm{Fe}^{3+}$ are potent emission quenchers, iron imaging within living cells encountered many challenges. Two early sensors, Calcein and Phen Green SK, exhibit turnoff responses to iron binding (Carter et al. 2014). However, both probes cannot adequately distinguish the two oxidation states of iron but can interact with other metal ions, leading to an interfering signal. In the past few years, a substantial body of efforts has been devoted toward construction of iron probes that may make a stunning breakthrough regarding cellular iron homeostasis.

$\mathrm{Fe}^{2+}$

The growing palette of chemodosimeters for $\mathrm{Fe}^{2+}$ mapping exploits the potent redox activity of this metal ion, and the last several years have witnessed a tremendous number of novel $\mathrm{Fe}^{2+}$ chemoprobes suitable for live-cell imaging experiments. Recent reviews by Hirayama, Aron and coworkers exhaustively profiled the development of molecular probes for $\mathrm{Fe}^{2+}$ (Aron et al. 2018; Hirayama 2019). A palette of $\mathrm{Fe}^{2+}$-mediated principles have been reported, including $\mathrm{N}$-oxide or nitroxide reduction, cyclization, $\mathrm{O}_{2}$ activation and endoperoxide cleavage (Fig. 10).

$N$-oxide reduction The deoxygenation of tertiary amine $\mathrm{N}$-oxide is preferably mediated by $\mathrm{Fe}^{2+}$ as it has a lower redox state than $\mathrm{Fe}^{3+}$. Utilizing the reaction, Hirayama and coworkers developed the first turn-on fluorescent $\mathrm{Fe}^{2+}$ probe RhoNox-1 (Hirayama et al. 2013), which has been commercially available and applied to detecting $\mathrm{Fe}^{2+}$ changes during ferroptosis (Wang et al. 2019b). To date, this $\mathrm{Fe}^{2+}$ sensing strategy has emerged as the most widely used one, establishing a series of sensors. For instance, HMRhoNox for visualization of intracellular $\mathrm{Fe}^{2+}$ delivered by TF (Niwa et al. 2014), CoNox-1 and FluNox-1 for scrutiny of intracellular redox equilibrium shift toward $\mathrm{Fe}^{2+}$ in hypoxic HepG2 cells (Hirayama et al. 2017), and a membrane-anchoring probe Mem- 
A

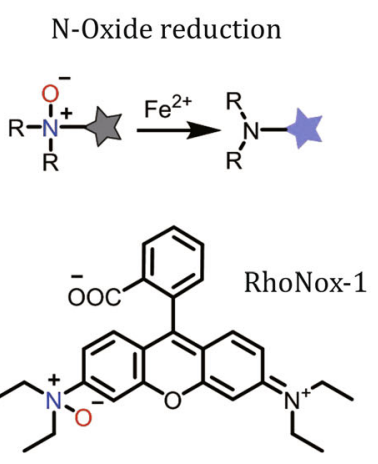

B

Nitroxide reduction
C

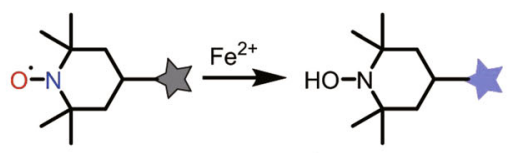

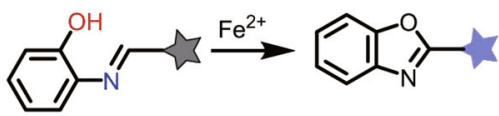<smiles>CCOc1ccc2cc(/C=N/c3ccccc3O)c(=O)oc2c1</smiles>

L1
D<smiles>O=C(O)COCc1cccc(CN(CC(=O)O)C(c2ccccn2)c2ccccn2)n1</smiles><smiles></smiles>

E Endoperoxide cleavage

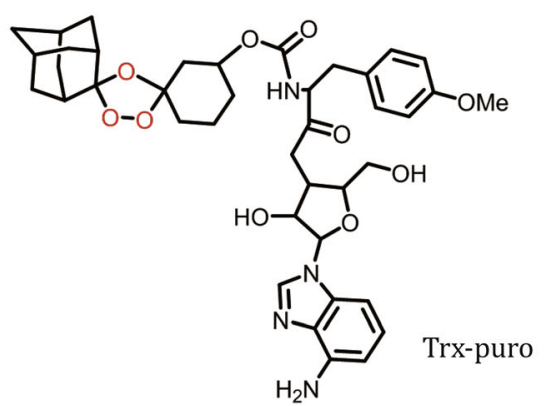

Fig. 10 Reaction-based sensing probes for $\mathrm{Fe}^{2+}$ detection. A N-oxide: RhoNox-1. B Nitroxide reduction: Rh-T. C Cyclization: L1. D $\mathrm{O}_{2}$ activation: LCy7. E Endoperoxide cleavage: Trx-puro

RhoNox to scrutinize $\mathrm{Fe}^{2+}$ release during endocytotic iron uptake (Niwa et al. 2018).

Recent research expanded the applicability to establish a series of organelle-specific fluorescent probes selective to $\mathrm{Fe}^{2+}$, i.e., MtFluNox, Lyso-RhoNox, ER-SiRhoNox and Gol-SiRhoNox. The former three chemosensors (Fig. 11) demonstrated similar off/on contrast and reaction rates $\left(2.1 \times 10^{-3} \mathrm{~s}^{-1}, 2.2 \times 10^{-3} \mathrm{~s}^{-1}\right.$, and $1.7 \times 10^{-3} \mathrm{~s}^{-1}$ ), investigated $\mathrm{Fe}^{2+}$ specifically at the targeted organelles (PCC $=0.81,0.80,0.80)$ and depicted fluorescence enhancement at $535 \mathrm{~nm}$ (green, 100 -fold), $575 \mathrm{~nm}$ (orange, 60-fold) and $660 \mathrm{~nm}$ (magenta, 60 -fold), respectively. Furthermore, these probes indicated the aberrant elevation of labile $\mathrm{Fe}^{2+}$ levels in the lysosomes and ER but no $\mathrm{Fe}^{2+}$ fluctuation in the mitochondria prior to HT1080 cell death initiated by erastin (Hirayama et al. 2019b).

As depicts in Fig. 1, DMT1 serves as a primary transporter of $\mathrm{Fe}^{2+}$. Over the course of the endocytotic process, directing DMT1 toward the cellular membrane via the trans-Golgi network is partially regulated by a retromer-mediated protein-sorting machinery comprising vacuolar protein-sorting proteins (VPSs) (Burd and
Cullen 2014). Therefore, the Golgi organelle functions as a node in this dynamic system for intracellular $\mathrm{Fe}^{2+}$ species along with DMT1. Dysfunction of VPSs, particularly the mutation of VPS35, can activate the aberrant delivery of DMT1 to lysosomes concomitantly with $\mathrm{Fe}^{2+}$ ions (Tabuchi et al. 2010). The last one Gol-SiRhoNox revealed an abnormal cellular $\mathrm{Fe}^{2+}$ distribution induced by dysfunction of VPS35 with a molecular chaperone R55 (Hirayama et al. 2019a).

Nitroxide reduction In parallel studies, a related $\mathrm{Fe}^{2+}$. promoted nitroxide reduction reaction has been employed for reaction-based sensing of $\mathrm{Fe}^{2+}$ (Maiti et al. 2015). A rhodamine-linked nitroxide probe, Rh-T, bears a pendant paramagnetic 2,2,6,6-tetramethylpiperidine1-oxyl (TEMPO) group that quenches fluorescence. $\mathrm{Fe}^{2+}$ reduces the receptor radical to a diamagnetic hydroxylamine, resulting in a significant fluorescence turn-on $(\sim 2.5$-fold $)$ with a LOD $\sim 0.75 \mu \mathrm{mol} / \mathrm{L} . \mathrm{Fe}^{2+}$-dependent reduction of the TEMPO radical of Rh-T triggers both a fluorescence turn-on and a change in electron paramagnetic resonance (EPR) signal. Following this example, Zhu group reported NT-Fe with the fastest 

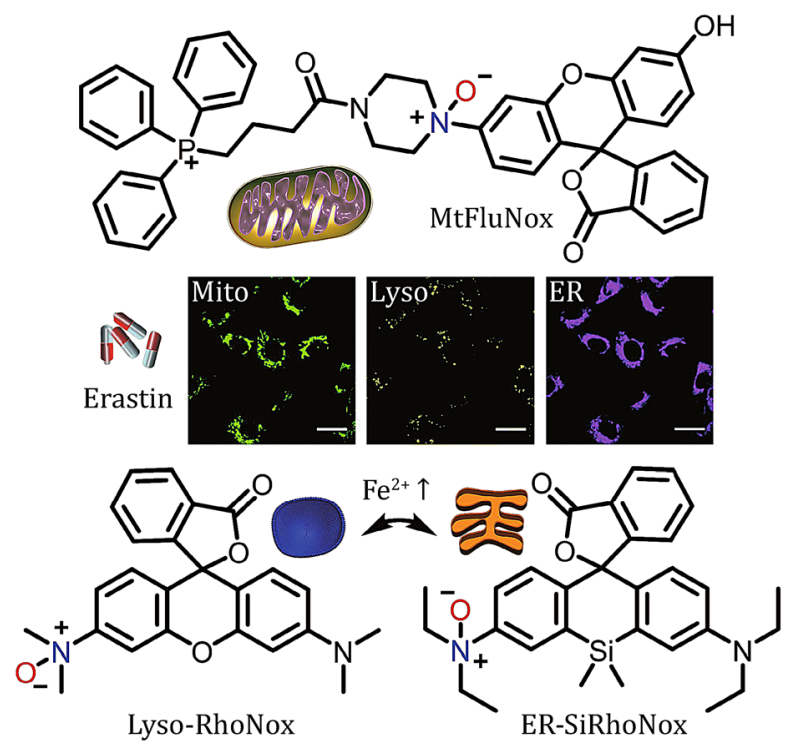

Fig. 11 Chemical structures of the fluorescent $\mathrm{Fe}^{2+}$ probes used MtFluNox, Lyso-RhoNox and ER-SiRhoNox. And fluorescence microscopic analysis for multi-color detection of $\mathrm{Fe}^{2+}$ at each targeted organelle. Adapted from Hirayama et al. (2019b)

response $(<50 \mathrm{~s})$, as well as the sensitive LOD of $89 \mathrm{nmol} / \mathrm{L}$ (Zhang et al. 2020). In zebrafish, NT-Fe responds to the addition of exogenous $\mathrm{Fe}^{2+}$, and its signal decreases when pretreated with $\mathrm{Fe}^{2+}$ scavenger 2,2'-bipyridine (Bpy).

Cyclization By exploiting the Lewis acidity of $\mathrm{Fe}^{2+}$, a recent report highlighted the application of an $\mathrm{Fe}^{2+}$. specific cyclization of a phenolic unit adjacent to a $\mathrm{C}=\mathrm{N}$ bond appended to a coumarin derivative (Long et al. 2018). Upon cyclization, generation of a benzoxazole ring handicaps $\mathrm{C}=\mathrm{N}$ bond isomerization and rotation, turning on fluorescence in aqueous solution and HepG2 cells, which has also been confirmed by TD-DFT calculation. Significantly, the sensing reaction completed in $2 \mathrm{~min}$ with high sensitivity (LOD $=45 \mathrm{nmol} / \mathrm{L}$ ). However, more analogous probes should be rationally constructed to verify the validity of the proposed mechanism.

$\mathrm{O}_{2}$ activation Prior work by Chang laboratory on creating $\mathrm{Cu}^{+}$indicators presaged the general utility of biomimetic oxygen activation for $\mathrm{Fe}^{2+}$ surveillance. Inspired by the $\mathrm{O}_{2}$ chemistry of $\mathrm{Fe}^{2+}$, and in particular, the 2-His-1-carboxylate triad motif found in mononuclear non-heme $\mathrm{Fe}^{2+}$ enzymes (cytochrome P450), they engineered iron probe 1 (IP1) (Au-Yeung et al. 2013). IP1 was capable of monitoring elevated intracellular labile $\mathrm{Fe}^{2+}$ levels in HepG2/C3A cells caused by treatment with hepcidin or ascorbic acid.

Replacement of the fluorescein alcohol substituent with a cyanine dye (Cy7), the Tang group yielded another NIR fluorescent probe (LCy7) (Wu et al. 2020), comprising a tris(pyridine) carboxylate-type ligand cage as an iron recognition and activity site. Upon $\mathrm{Fe}^{2+}$ coordination, $\mathrm{O}_{2}$ activation triggers intramolecular $\mathrm{C}-\mathrm{O}$ bond cleavage and oxidation to release the fluorophore, resulting in an increase $(\sim 3.7$-fold $)$ in the fluorescence emission peaked at $690 \mathrm{~nm}$. Utilizing LCy7, dynamic $\mathrm{Fe}^{2+}$ enhancement was distinctly monitored in HL-7702 cells under ER stress by acetaminophen (APAP) stimulation. in vivo FLI disclosed the conspicuous $\mathrm{Fe}^{2+}$ ascent in the liver of mice during drug-induced liver injury (DILI).

Endoperoxide cleavage Motivated by $\mathrm{Fe}^{2+}$-reactive endoperoxide activation observed in antimalarial drugs (e.g., Artemisinin), Renslo and coworkers designed Trxpuro, a histochemical stain for labile $\mathrm{Fe}^{2+}$ comprised of a trioxalane-caged puromycin (Spangler et al. 2016). Upon reaction of the probe with $\mathrm{Fe}^{2+}$, free puromycin is released, which can be translated onto nascent peptides and quantified via a conventional immunostaining method by a puromycin antibody after fixation. Application of Trx-puro to a panel of cancer cells (PC-3, U-2 OS, MCF10A and RKO) reveals FTN/FPN overexpression and declined $\mathrm{Fe}^{2+}$ stores. Linking fluorescein and $\mathrm{Cy} 3$ through this bioinspired endoperoxide trigger, Chang et al. envisioned FRET iron probe 1 (FIP-1) for ratiometric fluorescence $\mathrm{Fe}^{2+}$ imaging upon 35MEW28-induced ferroptosis in MDA-MB-231 cells (Aron et al. 2016).

Expanding the scope of oxidative cleavage to BLI, the same group then reported the first bioluminescent indicator for $\mathrm{Fe}^{2+}$ (Aron et al. 2017), iron-caged luciferin-1 (ICL-1), to surveil labile $\mathrm{Fe}^{2+}$ accumulation in a luciferase-expressing murine $\left(\mathrm{FVB}^{\left.-\mathrm{Luc}^{+}\right)}\right.$model of Acinetobacter (A.) baumannii infection (Fig. 12). The probe also retains high selectivity and sensitivity for $\mathrm{Fe}^{2+}$ over a variety of biologically relevant metal ions, oxidants and reductants and is feasible for detecting both $\mathrm{Fe}^{2+}$ rise and fall in PC3M-luc cells and other $\mathrm{Fe}^{2+}$. supplemented/depleted models.

Despite the exquisite selectivity toward $\mathrm{Fe}^{2+}$ for bioimaging, these reaction-based probes were not shown to have a reversible monitoring mode, hampering the capability to probe $\mathrm{Fe}^{2+}$ fluxes. If a probe is able to synchronously measure $\mathrm{Fe}^{2+}$ and $\mathrm{Fe}^{3+}$ without interference from other metal ions, the privileged part of iron taking in ferroptosis will no longer remain a mystery. 


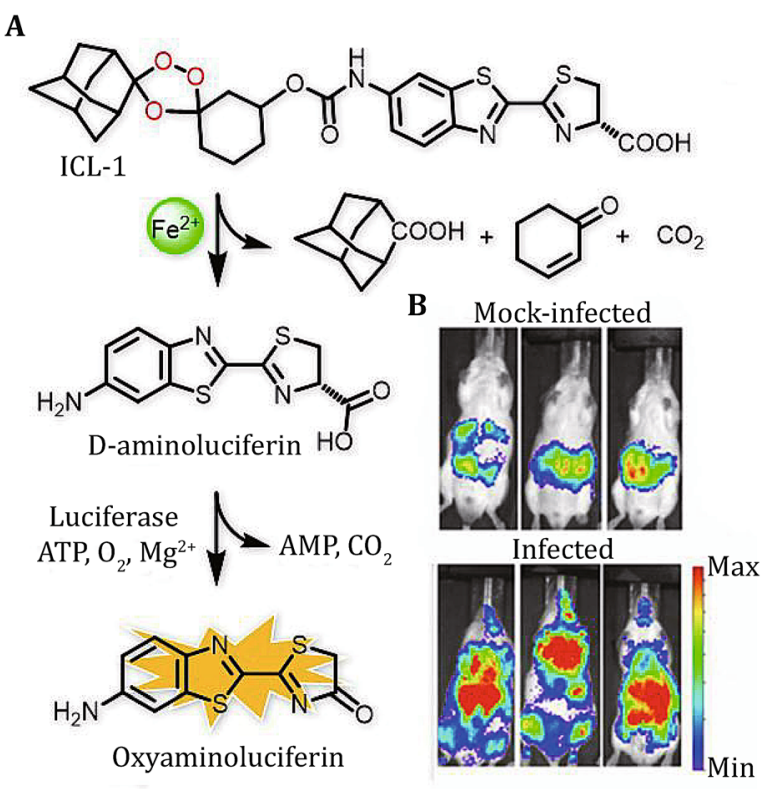

Fig. $12 \mathrm{~A} \mathrm{Fe}^{2+}$-selective cleavage of ICL-1, an endoperoxideluciferin conjugate and in vivo probe of $\mathrm{Fe}^{2+}$. $\mathbf{B}$ Representative images of FVB-Luc ${ }^{+}$mice mock-infected (PBS) or infected with $A$. baumannii through retroorbital injection (dorsal images at $30 \mathrm{~min}$ postinjection of ICL-1) and imaged with ICL-1 (25 nmol) at $24 \mathrm{~h}$ postinfection. Adapted from Aron et al. (2017)

$\mathrm{Fe}^{3+}$

In contrast to the growing usage of chemical probes for bioimaging of $\mathrm{Fe}^{2+}$, measurement of $\mathrm{Fe}^{3+}$ in biological environments is rarer. Sahoo et al. reviewed advances on $\mathrm{Fe}^{3+}$-specific fluorescent probes (Sahoo and Crisponi 2019; Sahoo et al. 2012). Due to the paramagnetic nature of ferric iron, its previous recognition by fluorescent probes involves different quenching mechanisms, which is improper for bioimaging applications. A new class of turn-on $\mathrm{Fe}^{3+}$ sensors can be classified into two major categories, chelation and spirolactam ringopening (Fig. 13). Furthermore, some ratiometric sensors recognizing the metal with an appropriate ligand group have been proposed to interrogate intracellular $\mathrm{Fe}^{3+}$ ions.

Turn-on $\mathrm{Fe}^{3+}$ probes Chelation The modularity of the PET platform has been applied to developing $\mathrm{Fe}^{3+}$ triggered fluorescent turn-on probes with enhanced properties. A novel PET-based reversible fluorescence turn-on probe $\mathrm{L} 2$ for selective assay of $\mathrm{Fe}^{3+}$ was introduced (Sui et al. 2014). The probe was comprised of BODIPY fluorophore with a 1,10-diaza-18-crown-6based cryptand that acted as the analyte binding unit.
Upon addition of $\mathrm{Fe}^{3+}$ in aqueous media $\left(\mathrm{H}_{2} \mathrm{O} / \mathrm{CH}_{3}\right.$ $\mathrm{CN}=9: 1$ ), the weakly fluorescent L2 (PET process is active) displayed 23-fold fluorescence enhancement at $512 \mathrm{~nm}\left(\lambda_{\mathrm{ex}}=480 \mathrm{~nm}\right)$. The significant fluorescence enhancement occurred due to inhibition of PET from cryptand to BODIPY fluorophore upon complexation with $\mathrm{Fe}^{3+}$. The probe displayed a LOD of $0.13 \mu \mathrm{mol} / \mathrm{L}$ and was applied to sensing intracellular $\mathrm{Fe}^{3+}$ ions in HCT-116 cells.

Our group introduced a simple anthracene-based fluorescent turn-on probe L3 containing $\mathrm{N}^{2}$-hydroxyethyldiethylenetriamine (HEDTA) for inferring $\mathrm{Fe}^{3+}$ concentrations (Qiu et al. 2014). When excited at $373 \mathrm{~nm}$, the $[2+2]$ macrocycle fluorescent sensor $(20 \mathrm{mmol} / \mathrm{L}$ Tris- $\mathrm{HCl} / \mathrm{MeOH}=1: 1, \mathrm{pH}$ 7.2) exhibits weak emission at 398, 421 and $447 \mathrm{~nm}$. In the presence of $\mathrm{Fe}^{3+}$, the formation of a $\mathrm{L} 3-\mathrm{Fe}^{3+}$ complex in 1:2 ratio restricts the PET process, causing significant fluorescence enhancement. Probe L3 shows a linear response ranging from 1 to $10 \mu \mathrm{mol} / \mathrm{L}$ with the LOD of $0.58 \mu \mathrm{mol} / \mathrm{L} \mathrm{Fe}^{3+}$. Confocal imaging disclosed that the probe possesses the ability of tracing cytosolic $\mathrm{Fe}^{3+}$ in SKOV-3 cells.

Spirolactam ring-opening Subsequently, we took advantage of the HEDTA ligand to develop another turnon $\mathrm{Fe}^{3+}$ probe Mito-RhFe by appending the HEDTA receptor onto rhodamine $B$ as a cationic, lipophilic tag to localize the probe to mitochondria (Zhu et al. 2018). In UV-Vis $\mathrm{Fe}^{3+}$ titration of this probe $(20 \mathrm{mmol} / \mathrm{L}$ Tris$\mathrm{HCl} / \mathrm{MeOH}=1: 1, \mathrm{pH} 7.2$ ), the solution color changes from colorless to magenta, thereby offering Mito-RhFe as an $\mathrm{Fe}^{3+}$-induced 'naked-eye' chemosensor. With this probe, the mitochondrial labile $\mathrm{Fe}^{3+}$ fluctuation in adherent HeLa cells $(P C C=0.90)$ upon ferric ammonium citrate (FAC) incubation was visualized via confocal imaging, and the flow cytometric assay for mitochondrial $\mathrm{Fe}^{3+}$ in suspension MEL cells, which is difficult to be monitored in an imaging manner, was also developed. Erythroid differentiation is normally accompanied by hemoglobin biosynthesis and upregulation of the mitochondrial iron importing protein mitoferrin-1 (MFRN1) containing ISC (Shaw et al. 2006). Interestingly, the labile $\mathrm{Fe}^{3+}$ drop in mitochondria of human K562 erythroleukemia cells undergoing the DMSO-stimulated erythroid differentiation was observed for the first time (Fig. 14).

In addition to $\mathrm{Zn}^{2+}$ and $\mathrm{Cu}^{2+}, \mathrm{Fe}^{3+}$ can trigger the hydrolysis and spirolactam ring-opening process of rhodamine derivatives, which has provided a valuable method to design $\mathrm{Fe}^{3+}$-selective luminescent sensors with a turn-on response. Lee et al. have presented six rhodamine-derived Schiff base probes' selectivity of the $\mathrm{Fe}^{3+}$ ion in biological systems (Lee et al. 2016). After 

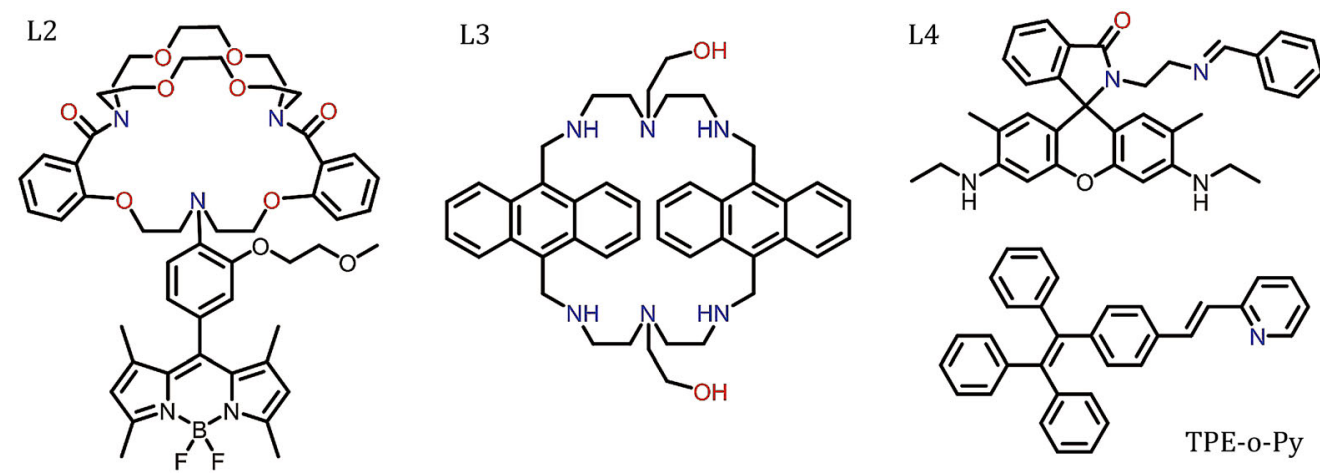

Fig. 13 Selected structures of $\mathrm{Fe}^{3+}$ probes. Turn-on sensors. A Chelation: L2 and L3. B Spirolactam ring-opening: L4, and ratiometric probe TPE-o-Py
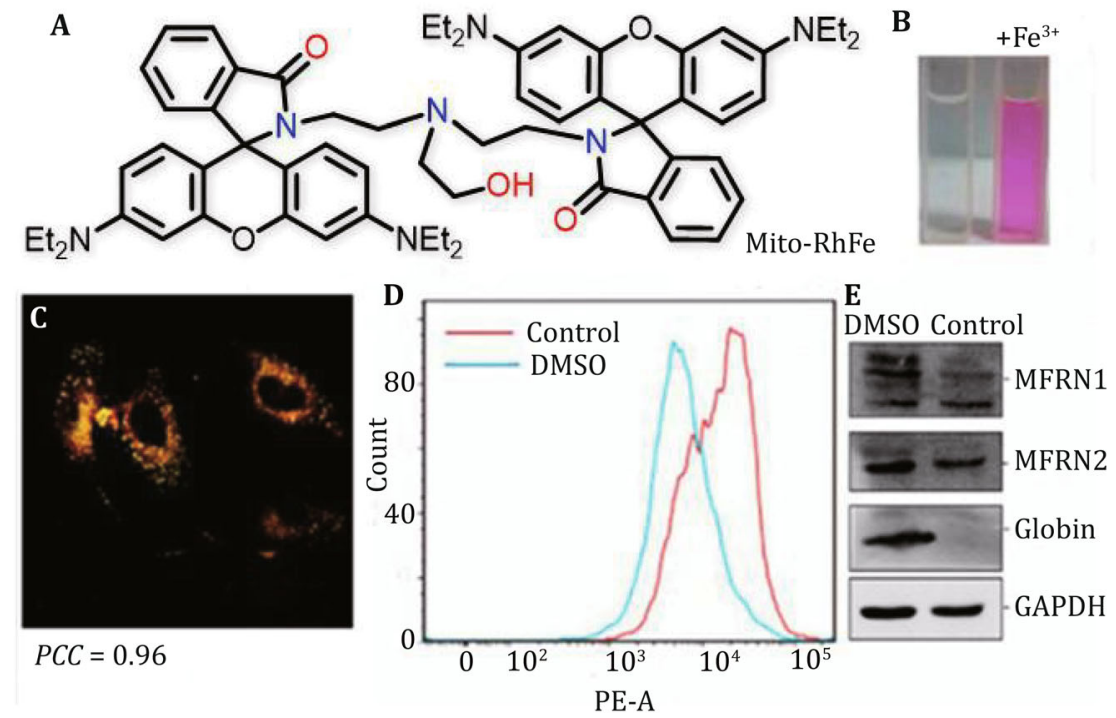

Fig. 14 A Chemical structure of probe Mito-RhFe. B Photograph of Mito-RhFe solution before (left) and after (right) $\mathrm{Fe}^{3+}$ addition $(20 \mathrm{mmol} / \mathrm{L}$ Tris- $\mathrm{HCl} / \mathrm{MeOH}=1: 1, \mathrm{pH}$ 7.2). C Colocalization of Mito-RhFe with MitoTracker deep red 633 in MCF-7 cells. The cells were stained firstly by $10 \mu \mathrm{mol} / \mathrm{L}$ probe in PBS for $30 \mathrm{~min}$ at $37^{\circ} \mathrm{C}$. D Labile $\mathrm{Fe}^{3+}$ flow cytometric assay of K562 cells incubated in RPMI1640 medium containing $2 \%$ DMSO. E Western blot analysis of the cells in D. The cells were cultured at $37{ }^{\circ} \mathrm{C}$ for 4 days, and stained with Mito$\mathrm{RhFe}$ at $0{ }^{\circ} \mathrm{C}$ for $30 \mathrm{~min}$ before assay. Cells cultured without DMSO were adopted as the control. Adapted from Zhu et al. (2018)

exposure to $\mathrm{Fe}^{3+}$, the probes appeared a new absorption peak at $526 \mathrm{~nm}$, with a concomitant emission maximum at $551 \mathrm{~nm}$. Confocal microscopic analysis showcased that these probes underwent turn-on changes caused by cellular $\mathrm{Fe}^{3+}$ ions, and demonstrated a largely enhanced fluorescence upon iron overloading of the HepG2 cell line. They also found that the $\mathrm{Fe}^{3+}$-mediated fluorescence augmentation was mainly localized in the ER. Among them, probe L5 exhibited the highest selectivity for ER localization $(P C C=0.7854)$ over other organelles.

Ratiometric sensors for $\mathrm{Fe}^{3+}$ Ratiometric probes are highly valued because their intrinsic internal standard can correct potential variations in light intensity, dye localization and other experimental imaging conditions (Ackerman et al. 2017). The aforementioned two turnon platforms can be adapted to quantify labile $\mathrm{Fe}^{3+}$ concentrations in a ratiometric readout, such as a bithiazole derivative (Geng et al. 2016), and a spirolactam analog RQBTE (Das et al. 2016).

It has been reported that ftn-1 (encoding the iron sequestering protein FTN) is upregulated in the presence of exogenous FAC supplementation, and downregulated upon treatment with an iron chelator deferoxamine (DFO) in the nematode Caenorhabditis (C.) elegans (Valentini et al. 2012). Goel et al. created the first dual colorimetric and ratiometric fluorescent $\mathrm{Fe}^{3+}$ 
probe NAP-3 (Goel et al. 2015), consisting of a naphtho[2,1-b]-[1,10]-phenanthroline (NAP). After exposure to increasing concentrations of $\mathrm{Fe}^{3+}$ ions (DMSO/ $\mathrm{H}_{2} \mathrm{O}=1: 9, \mathrm{pH} 7.4$ ), a new peak with maximum at $605 \mathrm{~nm}$ emerged and the peak at $544 \mathrm{~nm}$ decreased in the emission spectrum, with a final enhancement factor $\left(\mathrm{I}_{605} / \mathrm{I}_{544}\right)$ over 8.5 -fold. It can approximately measure as low as $9.1 \mathrm{nmol} / \mathrm{L} \mathrm{Fe}^{3+}$. Possibly due to steric hindrance, $\mathrm{Fe}^{3+}$ chelator DFO failed to remove $\mathrm{Fe}^{3+}$ from the complex (NAP-3/ $\mathrm{Fe}^{3+}$ ). Common ions do not imply any significant interference in the determination of $\mathrm{Fe}^{3+}$ ion. The indicator enabled direct visualization of exogenous $\mathrm{Fe}^{3+}$ in HepG2 cells, and endogenous $\mathrm{Fe}^{3+}$ in a multicellular organism, ftn-1 silenced $C$. elegans (Fig. 15).

In fact, most conventional organic dyes exhibit aggregation-caused quenching (ACQ) when aggregated. Aggregation-induced emission (AIE) phenomena, originating from the restriction of intramolecular motions (RIM), is thus a unique turn-on approach for addressing the ACQ issue (Chen et al. 2018). AIE luminogens (AIEgens) tend to behave in a non-emissive manner when well dissolved in some solvents, but emit intense fluorescence when poorly dissolved by means of forming aggregates (Mei et al. 2015). AIEgens have emerged as a powerful methodology for the assay of transition metal ions such as $\mathrm{Zn}^{2+}$ (Jung et al. 2015), $\mathrm{Cu}^{2+}$ (Feng et al. 2014) and $\mathrm{Hg}^{2+}$ (Chen et al. 2016).

By making use of the position-dependent substituent effects, an AIE featured $\mathrm{Fe}^{3+}$ probe (TPE-o-Py) from ortho-substituted pyridinyl-functionalized tetraphenylethylene is synthesized by Tang's research group (Feng et al. 2018). From weak blue to strong red emission (peak $472 \mathrm{~nm}$ to $573 \mathrm{~nm}$ ) under $365 \mathrm{~nm}$ UV irradiation, TPE-o-Py displays high metal selectivity and oxidation-state specificity ( $\left.\mathrm{THF} / \mathrm{H}_{2} \mathrm{O}=3: 7\right)$ arising from the position isomer of ortho-substitution. And it has a low acid dissociation constant $\left(\mathrm{p} K_{\mathrm{a}} \sim 3.27\right)$ that is close to that of hydrolyzed $\mathrm{Fe}^{3+}$. More importantly, the light-up fluorescent probe TPE-o-Py can be applied to sensing $\mathrm{Fe}^{3+}$ in HeLa cells with a pronounced red shift in fluorescence emission.

It should be noted that the reduction potential in the cytosol favors $\mathrm{Fe}^{2+}$ over $\mathrm{Fe}^{3+}$ (Aron et al. 2018), and $\mathrm{Fe}^{3+}$ is poorly soluble at neutral $\mathrm{pH}$ in aqueous media. On the other hand, the vast majority of $\mathrm{Fe}^{3+}$ probes have not been well suited for endogenous investigations due to a lack of high sensitivity. In this context, exploring improved motifs to decode $\mathrm{Fe}^{3+}$ roles in biology is of tremendous significance.

\section{SUMMARY AND PERSPECTIVES}

In this review, we summarized endeavors made in molecular imaging for transition metal cations. Specifically, we highlighted synthetic sensors that are utilized to image zinc, copper and iron in biological systems (Table 2). Great challenges still remain in the field to be confronted with:

(A) Expanding metal probes bioavailable. It is the quality of probes, including solubility, sensitivity and selectivity (3S), not the quantity that matters. Deliberate design of metal sensors with improved bioavailability is of paramount importance. In addition, other transition metals like manganese

B

A

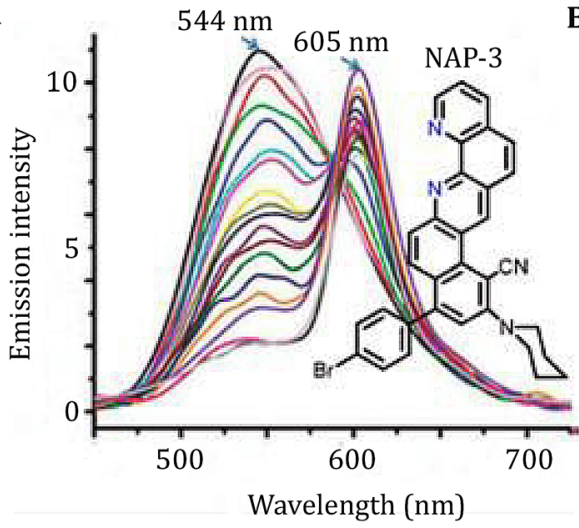

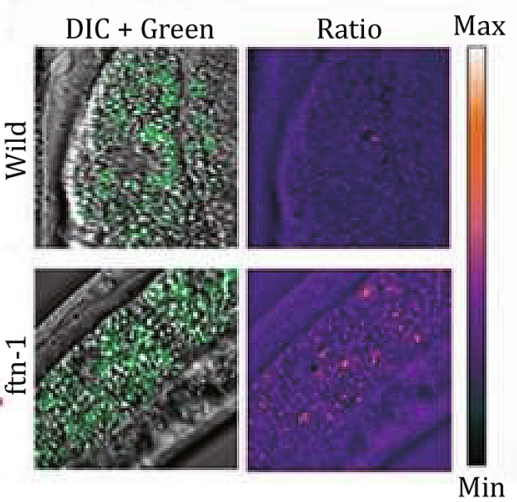

Fig. 15 A Ratiometric fluorescence spectra (DMSO $\left./ \mathrm{H}_{2} \mathrm{O}=1: 9, \mathrm{pH} 7.4\right)$ of $25 \mu \mathrm{mol} / \mathrm{L} \mathrm{NAP-3}\left(\lambda_{\text {ex }}=365 \mathrm{~nm}\right.$ ) after $1 \mathrm{~h}$ upon addition of increasing concentrations of $\mathrm{Fe}^{3+}(0-0.68 \mathrm{mmol} / \mathrm{L})$. Inset in A: chemical structure of NAP-3. B Wild-type and ftn-1 silenced $C$. elegans treated with NAP-3 ( $3 \mu \mathrm{mol} / \mathrm{L}, 24 \mathrm{~h}$ ). Green channel images obtained with a bandpath of 505-550 $\mathrm{nm}$ upon excitation at $405 \mathrm{~nm}$, red channel images obtained with $575 \mathrm{~nm}$ long pass upon excitation at $561 \mathrm{~nm}$, and the corresponding ratiometric images $\left(F_{\text {red }} / F_{\text {green }}\right)$. Adapted from Goel et al. (2015) 
Table 2 Summary of selected probes for metal detection

\begin{tabular}{|c|c|c|c|c|}
\hline Probe & Modality & Readout & Cells & Biological highlights \\
\hline $\begin{array}{l}\text { DA-ZP1- } \\
\text { TPP }\end{array}$ & FLI & $\mathrm{F}_{529}$ & $\begin{array}{l}\text { HeLa, WPE-1, RWPE- } \\
\text { 2, PC-3 }\end{array}$ & Mobile $\mathrm{Zn}^{2+}$ in mitochondria of healthy vs cancerous prostate cells \\
\hline $\begin{array}{l}\text { LysoDPP- } \\
\text { C4 }\end{array}$ & FLI & $\mathrm{F}_{515}$ & HeLa, PC-3, DU145 & Cancerous prostate nodules via $\mathrm{Zn}^{2+}$-induced fluorescence signaling \\
\hline CNSB & TPI & $\begin{array}{l}\mathrm{F}_{470} / \\
\mathrm{F}_{565}\end{array}$ & MCF-7 & Fluctuation and distribution of $\mathrm{Cu}^{+}$under ER stress in MCF-7 cells \\
\hline CCL-1 & BLI & n.d & PC3M-luc & $\mathrm{Cu}^{+}$deficiency in a murine model of non-alcoholic fatty liver disease \\
\hline RPS1 & PAI & $\mathrm{PA}_{710}$ & bEnd.3 & $\begin{array}{l}\text { Cross the blood-brain barrier for } \mathrm{Cu}^{2+} \text { visualization in mice with Alzheimer's } \\
\text { disease }\end{array}$ \\
\hline $\mathrm{NRh}$ & UCL & $\mathrm{UCL}_{730}$ & HeLa & In vivo detection of $\mathrm{Cu}^{2+}$ in Wilson disease \\
\hline LCy7 & FLI & $\mathrm{F}_{690}$ & HL-7702 & Labile $\mathrm{Fe}^{2+}$ in ER stress-mediated drug-induced liver injury \\
\hline ICL-1 & BLI & n.d & PC3M-luc & Labile $\mathrm{Fe}^{2+}$ accumulation in a murine model of $A$. baumannii infection \\
\hline $\begin{array}{l}\text { Mito- } \\
\text { RhFe }\end{array}$ & FLI & $\mathrm{F}_{580}$ & MCF-7 & $\begin{array}{l}\text { Labile } \mathrm{Fe}^{3+} \text { drop in mitochondria of K562 cells undergoing the DMSO- } \\
\text { stimulated erythroid differentiation }\end{array}$ \\
\hline NAP-3 & FLI & $\begin{array}{l}\mathrm{F}_{605} / \\
\mathrm{F}_{544}\end{array}$ & HepG2 & Endogenous labile $\mathrm{Fe}^{3+}$ pools in $\mathrm{ftn}-1$ silenced $C$. elegans \\
\hline
\end{tabular}

"n.d.": not determined. TPI and UCL belong to FLI

(Mn) also take active part in health and disease (Avila et al. 2013). Yet Mn sensors are still on an early stage, and there have been far fewer smallmolecule probes prepared for $\mathrm{Mn}^{2+}$ detection (Bakthavatsalam et al. 2015; Liang and Canary 2010).

(B) Combining super-resolution techniques. Super-resolution techniques, such as stimulated emission depletion (STED), structured illumination microscopy (SIM) and stochastic optical reconstruction microscopy (STORM), provide a valuable starting point to study analytes in nano-dimension (Kozma and Kele 2018). Application of this technique to molecular probes for mapping metals is an important and arduous task.

(C) Designing dual-responsive probes. Using two selective probes simultaneously to monitor multiple species is troublesome, and it is therefore preferable to pursue dual-responsive single probes, operating as a logic gate in response to two elements (Kolanowski et al. 2018). In this case, interrelations between multiple elements in biology can be deciphered. For instance, if a probe is able to synchronously measure $\mathrm{Cu}^{+}$and GSH without any interference from other analytes, more straightforward data would be offered with less work in NAFLD mentioned above.

(D) Mining multi-mode imaging. Given that diverse imaging modes can be complementary, our laboratory recently reported a FLI/PAI dual-modality probe HS-CyBz (Chen et al. 2019a, b), realizing ratiometric in/ex vivo tracking for stimulated $\mathrm{H}_{2} \mathrm{~S}$ fluctuations in mice. Integrating several imaging modes into a single metal probe should be appropriately achieved in the longer term.

To sum up, roles for labile metals in cells and tissues have been elucidated to a certain extent using these molecular probes. Continued innovations in exploiting chemical reagents, in cooperation with physicists and biologists, presage further opportunities for uncovering how metal cations work in biology.

Acknowledgements The work was under financial supports from the National Natural Science Foundation of China (21977044, 21907050, 21731004, 91953201), the Natural Science Foundation of Jiangsu Province (BK20190282) and the Excellent Research Program of Nanjing University (ZYJH004). We thank Dr. Chengcheng Zhu, Dr. Lin Qiu and Ms. Jungu Guo for offering the original images shown in abstract. We also thank sincere friends Miss Xiaotong Li (NJUST) and Mr. Dong Han (USTC) for polishing up the writing.

\section{Compliance with Ethical Standards}

Conflict of interest Jing Gao, Yuncong Chen, Zijian Guo and Weijiang He declare that they have no conflict of interest.

Human and animals rights and informed consent This article does not contain any studies with human or animal subjects performed by any of the authors.

Open Access This article is licensed under a Creative Commons Attribution 4.0 International License, which permits use, sharing, adaptation, distribution and reproduction in any medium or format, as long as you give appropriate credit to the original author(s) and the source, provide a link to the Creative Commons licence, and indicate if changes were made. The images or other third party material in this article are included in the article's Creative Commons licence, unless indicated otherwise in a credit 
line to the material. If material is not included in the article's Creative Commons licence and your intended use is not permitted by statutory regulation or exceeds the permitted use, you will need to obtain permission directly from the copyright holder. To view a copy of this licence, visit http://creativecommons.org/ licenses/by/4.0/.

\section{References}

Ackerman CM, Lee S, Chang CJ (2017) Analytical methods for imaging metals in biology: from transition metal metabolism to transition metal signaling. Anal Chem 89(1):22-41

Andersson M, Mattle D, Sitsel O, Klymchuk T, Nielsen AM, Møller LB, White SH, Nissen P, Gourdon P (2014) Copper-transporting P-type ATPases use a unique ion-release pathway. Nat Struct Mol Biol 21(1):43-48

Andrews NC (2000) Iron metabolism: iron deficiency and iron overload. Annu Rev Genomics Hum Genet 1(1):75-98

Aron A, Heffern M, Lonergan Z, Wal M, Blank B, Spangler B, Zhang Y, Park HM, Stahl A, Renslo A, Skaar E, Chang C (2017) In vivo bioluminescence imaging of labile iron accumulation in a murine model of Acinetobacter baumannii infection. Proceedings of the National Academy of Sciences USA 114:201708747

Aron AT, Loehr MO, Bogena J, Chang CJ (2016) An endoperoxide reactivity-based FRET probe for ratiometric fluorescence imaging of labile iron pools in living cells. J Am Chem Soc 138(43):14338-14346

Aron AT, Ramos-Torres KM, Cotruvo JA, Chang CJ (2015) Recognition- and reactivity-based fluorescent probes for studying transition metal signaling in living systems. Acc Chem Res 48(8):2434-2442

Aron AT, Reeves AG, Chang CJ (2018) Activity-based sensing fluorescent probes for iron in biological systems. Curr Opin Chem Biol 43:113-118

Au-Yeung HY, Chan J, Chantarojsiri T, Chang CJ (2013) Molecular imaging of labile iron(ii) pools in living cells with a turn-on fluorescent probe. J Am Chem Soc 135(40):15165-15173

Avila DS, Puntel RL, Aschner M (2013) Manganese in health and disease. In: Sigel H, Sigel RKO, et al. (eds) Sigel A. Book. Manganese in health and disease. Dordrecht, Springer, Netherlands, pp 199-227

Baker M (2010) The whole picture. Nature 463(7283):977-979

Bakthavatsalam S, Sarkar A, Rakshit A, Jain S, Kumar A, Datta A (2015) Tuning macrocycles to design 'turn-on' fluorescence probes for manganese(ii) sensing in live cells. Chem Commun 51(13):2605-2608

Ballesteros E, Moreno D, Gómez T, Rodríguez T, Rojo J, GarcíaValverde M, Torroba T (2009) A new selective chromogenic and turn-on fluorogenic probe for copper(ii) in water-acetonitrile 1:1 solution. Org Lett 11(6):1269-1272

Bandmann 0, Weiss KH, Kaler SG (2015) Wilson's disease and other neurological copper disorders. The Lancet Neurology 14(1):103-113

Bansagi B, Lewis-Smith D, Pal E, Duff J, Griffin H, Pyle A, Müller JS, Rudas G, Aranyi Z, Lochmüller H, Chinnery PF, Horvath R (2016) Phenotypic convergence of Menkes and Wilson disease. Neurology Genetics 2(6):e119

Bertinato J, Iskandar M, Labbe MR (2003) Copper deficiency induces the upregulation of the copper chaperone for $\mathrm{Cu} / \mathrm{Zn}$ superoxide dismutase in weanling male rats. J Nutr 133(1):28-31
Bleackley MR, MacGillivray RTA (2011) Transition metal homeostasis: from yeast to human disease. Biometals 24(5):785-809

Brady DC, Crowe MS, Turski ML, Hobbs GA, Yao X, Chaikuad A, Knapp S, Xiao K, Campbell SL, Thiele DJ, Counter CM (2014) Copper is required for oncogenic BRAF signalling and tumorigenesis. Nature 509(7501):492-496

Braymer JJ, Lill R (2017) Iron-sulfur cluster biogenesis and trafficking in mitochondria. The Journal of biological chemistry 292(31):12754-12763

Burd C, Cullen PJ (2014) Retromer: a master conductor of endosome sorting. Cold Spring Harbor Perspectives in Biology 6(2):a016774

Cao X, Lin W, Wan W (2012) Development of a near-infrared fluorescent probe for imaging of endogenous $\mathrm{Cu}^{+}$in live cells. Chem Commun 48(50):6247-6249

Carter KP, Young AM, Palmer AE (2014) Fluorescent sensors for measuring metal ions in living systems. Chem Rev 114(8):4564-4601

Chang CJ (2015) Searching for harmony in transition-metal signaling. Nat Chem Biol 11(10):744-747

Chang CJ, James TD, New EJ, Tang BZ (2020) Activity-based sensing: achieving chemical selectivity through chemical reactivity. Acc Chem Res 53(1):1-1

Chen Y, Bai Y, Han Z, He W, Guo Z (2015) Photoluminescence imaging of $\mathrm{Zn}^{2+}$ in living systems. Chem Soc Rev 44(14):4517-4546

Chen Y, Lam J, Kwok R, Liu B, Tang B (2019a) Aggregation-induced emission: fundamental understanding and future developments. Materials Horizons 6:428-433

Chen Y, Zhang W, Cai Y, Kwok RTK, Tang BZ (2016) AIEgens for dark through-bond energy transfer: design, synthesis, theoretical study and application in ratiometric $\mathrm{Hg}(2+)$ sensing. Chemical science 8(3):2047

Chen Y, Zhu C, Cen J, Li J, He W, Jiao Y, Guo Z (2013) A reversible ratiometric sensor for intracellular $\mathrm{Cu}^{2+}$ imaging: metal coordination-altered FRET in a dual fluorophore hybrid. Chem Commun 49(69):7632-7634

Chen Z, Mu X, Han Z, Yang S, Zhang C, Guo Z, Bai Y, He W (2019b) An optical/photoacoustic dual-modality probe: ratiometric in/ex vivo imaging for stimulated $\mathrm{H} 2 \mathrm{~S}$ upregulation in mice. J Am Chem Soc 141(45):17973-17977

Chung CY-S, Posimo JM, Lee S, Tsang T, Davis JM, Brady DC, Chang CJ (2019) Activity-based ratiometric FRET probe reveals oncogene-driven changes in labile copper pools induced by altered glutathione metabolism. Proceedings of the National Academy of Sciences USA 116(37):18285-18294

Chyan W, Zhang D, Lippard S, Radford R (2014) Reaction-based fluorescent sensor for investigating mobile $\mathrm{Zn}^{2+}$ in mitochondria of healthy versus cancerous prostate cells. Proc Natl Acad Sci USA 111(1):143-148

Conrad M, Angeli JPF, Vandenabeele P, Stockwell BR (2016) Regulated necrosis: disease relevance and therapeutic opportunities. Nat Rev Drug Discovery 15(5):348-366

Costello LC, Feng P, Milon B, Tan M, Franklin RB (2004) Role of zinc in the pathogenesis and treatment of prostate cancer: critical issues to resolve. Prostate Cancer and Prostatic Diseases 7(2):111-117

Cotruvo JJA, Aron AT, Ramos-Torres KM, Chang CJ (2015) Synthetic fluorescent probes for studying copper in biological systems. Chem Soc Rev 44(13):4400-4414

Das S, Aich K, Goswami S, Quah CK, Fun H-K (2016) FRET-based fluorescence ratiometric and colorimetric sensor to discriminate $\mathrm{Fe}^{3+}$ from $\mathrm{Fe}^{2+}$. New J Chem 40(7):6414-6420

Dixon SJ, Stockwell BR (2014) The role of iron and reactive oxygen species in cell death. Nat Chem Biol 10(1):9-17 
Dodani SC, Firl A, Chan J, Nam CI, Aron AT, Onak CS, Ramos-Torres KM, Paek J, Webster CM, Feller MB, Chang CJ (2014) Copper is an endogenous modulator of neural circuit spontaneous activity. Proceedings of the National Academy of Sciences USA 111(46):16280-16285

Dong Z, Han Q Mou Z, Li G, Liu W (2018) A reversible frequency upconversion probe for real-time intracellular lysosome-pH detection and subcellular imaging. Journal of Materials Chemistry B 6(9):1322-1327

Du C et al (2019) Diketopyrrolopyrrole-based fluorescence probes for the imaging of lysosomal $\mathrm{Zn} 2+$ and identification of prostate cancer in human tissue. Chem Sci 10:5699-5704

Eide DJ (2004) The SLC39 family of metal ion transporters. Pflügers Archiv 447(5):796-800

Fahrni CJ (2013) Synthetic fluorescent probes for monovalent copper. Curr Opin Chem Biol 17(4):656-662

Feng H-T, Song S, Chen Y-C, Shen C-H, Zheng Y-S (2014) Selfassembled tetraphenylethylene macrocycle nanofibrous materials for the visual detection of copper(ii) in water. Journal of Materials Chemistry C 2(13):2353-2359

Feng X, Li Y, He X, Liu H, Zhao Z, Kwok RTK, Elsegood MRJ, Lam JWY, Tang BZ (2018) A substitution-dependent light-up fluorescence probe for selectively detecting $\mathrm{Fe}^{3+}$ ions and its cell imaging application. Adv Func Mater 28(35):1802833

Festa RA, Thiele DJ (2011) Copper: an essential metal in biology. Curr Biol 21(21):R877-R883

Friedmann Angeli JP, Krysko DV, Conrad M (2019) Ferroptosis at the crossroads of cancer-acquired drug resistance and immune evasion. Nat Rev Cancer 19(7):405-414

Geng J, Liu Y, Li J, Yin G, Huang W, Wang R, Quan Y (2016) A ratiometric fluorescent probe for ferric ion based on a 2,2'bithiazole derivative and its biological applications. Sensors and Actuators B: Chemical 222:612-617

Goel A, Umar S, Nag P, Sharma A, Kumar L, Shamsuzzama, Hossain Z, Gayen JR, Nazir A (2015) A dual colorimetric-ratiometric fluorescent probe NAP-3 for selective detection and imaging of endogenous labile iron(iii) pools in C. elegans. Chemical Communications 51(24):5001-5004

Guo J, Yuan H, Chen Y, Chen Z, Zhao M, Zou L, Liu Y, Liu Z, Zhao Q Guo Z, He W (2019) A ratiometric fluorescent sensor for tracking $\mathrm{Cu}(\mathrm{I})$ fluctuation in endoplasmic reticulum $<$ styleredit/ $>$. Science China Chemistry 62:465-474

Guo Z, Park S, Yoon J, Shin I (2014) Recent progress in the development of near-infrared fluorescent probes for bioimaging applications. Chem Soc Rev 43(1):16-29

Hassannia B, Vandenabeele P, Vanden Berghe T (2019) Targeting ferroptosis to iron out cancer. Cancer Cell 35(6):830-849

Heffern MC, Park HM, Au-Yeung HY, Van de Bittner GC, Ackerman CM, Stahl A, Chang CJ (2016) In vivo bioluminescence imaging reveals copper deficiency in a murine model of nonalcoholic fatty liver disease. Proceedings of the National Academy of Sciences USA 113(50):14219-14224

Hirayama $T$ (2019) Fluorescent probes for the detection of catalytic Fe(II) ion. Free Radical Biol Med 133:38-45

Hirayama T, Inden M, Tsuboi H, Niwa M, Uchida Y, Naka Y, Hozumi I, Nagasawa H (2019a) A Golgi-targeting fluorescent probe for labile Fe(ii) to reveal an abnormal cellular iron distribution induced by dysfunction of VPS35. Chemical science 10(5):1514-1521

Hirayama T, Miki A, Nagasawa H (2019b) Organelle-specific analysis of labile Fe(ii) during ferroptosis by using a cocktail of various colour organelle-targeted fluorescent probes. Metallomics 11(1):111-117

Hirayama T, Okuda K, Nagasawa H (2013) A highly selective turnon fluorescent probe for iron(ii) to visualize labile iron in living cells. Chemical science 4(3):1250-1256
Hirayama T, Tsuboi H, Niwa M, Miki A, Kadota S, Ikeshita Y, Okuda $\mathrm{K}$, Nagasawa $\mathrm{H}$ (2017) A universal fluorogenic switch for $\mathrm{Fe}(\mathrm{ii})$ ion based on $\mathrm{N}$-oxide chemistry permits the visualization of intracellular redox equilibrium shift towards labile iron in hypoxic tumor cells. Chemical science 8(7):4858-4866

Jin X, Wu X, Wang B, Xie P, He Y, Zhou H, Yan B, Yang J, Chen W, Zhang X (2018) A reversible fluorescent probe for $\mathrm{Zn}^{2+}$ and ATP in living cells and in vivo. Sensors and Actuators B: Chemical 261:127-134

Jung SH, Kwon K-Y, Jung JH (2015) A turn-on fluorogenic Zn(ii) chemoprobe based on a terpyridine derivative with aggregation-induced emission (AIE) effects through nanofiber aggregation into spherical aggregates. Chem Commun 51(5):952-955

Kelleher SL, McCormick NH, Velasquez V, Lopez V (2011) Zinc in specialized secretory tissues: roles in the pancreas, prostate, and mammary gland. Advances in Nutrition 2(2):101-111

Kim D, Ryu HG, Ahn KH (2014) Recent development of twophoton fluorescent probes for bioimaging. Org Biomol Chem 12(26):4550-4566

Knox HJ, Chan J (2018) Acoustogenic probes: a new frontier in photoacoustic imaging. Acc Chem Res 51(11):2897-2905

Kolanowski JL, Liu F, New EJ (2018) Fluorescent probes for the simultaneous detection of multiple analytes in biology. Chem Soc Rev 47(1):195-208

Kolenko V, Teper E, Kutikov A, Uzzo R (2013) Zinc and zinc transporters in prostate carcinogenesis. Nature Reviews Urology 10(4):219-226

Kozma E, Kele P (2018) Fluorogenic probes for super-resolution microscopy. Org Biomol Chem 17:215-233

Lazarczyk M, Favre M (2008) Role of $\mathrm{Zn}^{2+}$ ions in host-virus interactions. J Virol 82:11486-11494

Lee MH, Lee H, Chang MJ, Kim HS, Kang C, Kim JS (2016) A fluorescent probe for the $\mathrm{Fe}^{3+}$ ion pool in endoplasmic reticulum in liver cells. Dyes Pigm 130:245-250

Li H, Zhang P, Smaga LP, Hoffman RA, Chan J (2015) Photoacoustic probes for ratiometric imaging of copper(II). J Am Chem Soc 137(50):15628-15631

Li J, Chen L, Du L, Li M (2013) Cage the firefly luciferin! - a strategy for developing bioluminescent probes. Chem Soc Rev 42(2):662-676

Liang J, Canary JW (2010) Discrimination between hard metals with soft ligand donor atoms: an on-fluorescence probe for manganese(II). Angew Chem Int Ed 49(42):7710-7713

Lim B, Baek B, Jang K, Lee NK, Lee JH, Lee Y, Kim J, Kang SW, Park J, Kim S, Kang N-W, Hong S, Kim D-D, Kim I, Hwang H, Lee J (2019) Novel turn-on fluorescent biosensors for selective detection of cellular $\mathrm{Fe}^{3+}$ in lysosomes: thiophene as a selectivity-tuning handle for $\mathrm{Fe}^{3+}$ sensors. Dyes Pigm 169:51-59

Liu Y, Su Q, Chen M, Dong Y, Shi Y, Feng W, Wu Z-Y, Li F (2016) Near-infrared upconversion chemodosimeter for in vivo detection of $\mathrm{Cu}(2+)$ in Wilson disease. Advanced materials (Deerfield Beach, Fla.) 28(31):6625-6630

Liu Z, He W, Guo Z (2013) Metal coordination in photoluminescent sensing. Chem Soc Rev 42(4):1568-1600

Liu Z, Zhang C, Chen Y, Qian F, Bai Y, He W, Guo Z (2014) In vivo ratiometric $\mathrm{Zn}^{2+}$ imaging in zebrafish larvae using a new visible light excitable fluorescent sensor. Chem Commun 50(10):1253-1255

Loas A, Radford RJ, Lippard SJ (2014) Addition of a second binding site increases the dynamic range but alters the cellular localization of a red fluorescent probe for mobile zinc. Inorg Chem 53(13):6491-6493 
Long L, Wang N, Han Y, Huang M, Yuan X, Cao S, Gong A, Wang K (2018) A coumarin-based fluorescent probe for monitoring labile ferrous iron in living systems. Analyst 143(11):2555-2562

Maiti S, Aydin Z, Zhang Y, Guo M (2015) Reaction-based turn-on fluorescent probes with magnetic responses for $\mathrm{Fe} 2+$ detection in live cells. Dalton Trans 44(19):8942-8949

Mei J, Leung N, Kwok R, Jacky W, Tang B (2015) Aggregationinduced emission: together we shine, united we soar! Chem Rev 115(21):11718-11940

Müller UC, Deller T, Korte M (2017) Not just amyloid: physiological functions of the amyloid precursor protein family. Nat Rev Neurosci 18(5):281-298

Nishito Y, Kambe T (2018) Absorption mechanisms of iron, copper, and zinc: an overview. J Nutr Sci Vitaminol 64(1):1-7

Niwa M, Hirayama T, Okuda K, Nagasawa H (2014) A new class of high-contrast $\mathrm{Fe}(\mathrm{ii})$ selective fluorescent probes based on spirocyclized scaffolds for visualization of intracellular labile iron delivered by transferrin. Org Biomol Chem 12(34):6590-6597

Niwa M, Hirayama T, Oomoto I, Wang DO, Nagasawa H (2018) $\mathrm{Fe}(\mathrm{II})$ ion release during endocytotic uptake of iron visualized by a membrane-anchoring Fe(II) fluorescent probe. ACS Chem Biol 13(7):1853-1861

Palmiter RD, Huang L (2004) Efflux and compartmentalization of zinc by members of the SLC30 family of solute carriers. Pflügers Archiv 447(5):744-751

Paredes E, Das SR (2011) Click chemistry for rapid labeling and ligation of RNA. ChemBioChem 12(1):125-131

Park S, Kwon N, Lee J, Yoon J, Shin I (2020) Synthetic ratiometric fluorescent probes for detection of ions. Chem Soc Rev 49(1):143-179

Peter V, Kyoung S, Jong Seung K (2015) The role of copper ions in pathophysiology and fluorescent sensors for the detection thereof. Chem Commun 46(21):5556-5571

Prohaska JR, Broderius M, Brokate B (2003) Metallochaperone for $\mathrm{Cu}, \mathrm{Zn}$-superoxide dismutase (CCS) protein but not mRNA is higher in organs from copper-deficient mice and rats. Arch Biochem Biophys 417(2):227-234

Qian F, Zhang C, Zhang Y, He W, Gao X, Hu P, Guo Z (2009) Visible light excitable $\mathrm{Zn}^{2+}$ Fluorescent sensor derived from an intramolecular charge transfer fluorophore and its in vitro and in vivo application. J Am Chem Soc 131(4):1460-1468

Qiu L, Zhu C, Chen H, Hu M, He W, Guo Z (2014) A turn-on fluorescent $\mathrm{Fe}^{3+}$ sensor derived from an anthracene-bearing bisdiene macrocycle and its intracellular imaging application. Chem Commun 50(35):4631-4634

Reinhardt CJ, Chan J (2018) Development of photoacoustic probes for in vivo molecular imaging. Biochemistry 57(2):194-199

Sahoo SK, Sharma D, Bera RK, Crisponi G, Callan JF (2012) Iron(iii) selective molecular and supramolecular fluorescent probes. Chem Soc Rev 41(21):7195-7227

Shaw GC, Cope JJ, Li L, Corson K, Hersey C, Ackermann GE, Gwynn B, Lambert AJ, Wingert RA, Traver D, Trede NS, Barut BA, Zhou Y, Minet E, Donovan A, Brownlie A, Balzan R, Weiss MJ, Peters LL, Kaplan J, Zon LI, Paw BH (2006) Mitoferrin is essential for erythroid iron assimilation. Nature 440(7080):96-100

Shi Y, Wang R, Yuan W, Liu Q, Shi M, Feng W, Wu Z, Hu K, Li F (2018) Easy-to-use colorimetric cyanine probe for the detection of $\mathrm{Cu}^{2+}$ in Wilson's disease. ACS Appl Mater Interfaces 10(24):20377-20386

Shi Z, Tang X, Zhou X, Cheng J, Han Q, Zhou J-A, Wang B, Yang Y, Liu W, Bai D (2013) A Highly selective fluorescence "turn-on" probe for $\mathrm{Cu}(\mathrm{II})$ based on reaction and its imaging in living cells. Inorg Chem 52(21):12668-12673
Singh H, Lee HW, Heo CH, Byun JW, Sarkar AR, Kim HM (2015) A Golgi-localized two-photon probe for imaging zinc ions. Chem Commun 51(60):12099-12102

Spangler B, Morgan CW, Fontaine SD, Vander Wal MN, Chang CJ, Wells JA, Renslo AR (2016) A reactivity-based probe of the intracellular labile ferrous iron pool. Nat Chem Biol 12(9):680-685

Sui B, Tang S, Liu T, Kim B, Belfield KD (2014) Novel BODIPYbased fluorescence turn-on sensor for $\mathrm{Fe}^{3+}$ and its bioimaging application in living cells. ACS Appl Mater Interfaces 6(21):18408-18412

Szewczyk B (2013) Zinc homeostasis and neurodegenerative disorders. Frontiers in Aging Neuroscience 5(33)

Tabuchi M, Yanatori I, Kawai Y, Kishi F (2010) Retromer-mediated direct sorting is required for proper endosomal recycling of the mammalian iron transporter DMT1. J Cell Sci 123:756-766

Theil EC, Goss DJ (2009) Living with iron (and oxygen): questions and answers about iron homeostasis. Chem Rev 109(10):4568-4579

Trusso Sfrazzetto G, Satriano C, Tomaselli GA, Rizzarelli E (2016) Synthetic fluorescent probes to map metallostasis and intracellular fate of zinc and copper. Coord Chem Rev 311:125-167

Valentini S, Cabreiro F, Ackerman D, Alam M, Kunze M, Kay C, Gems D (2012) Manipulation of in vivo iron levels can alter resistance to oxidative stress without affecting ageing in the nematode C. mechanisms of ageing and development 133: 282-290

Valko M, Jomova K, Rhodes CJ, Kuča K, Musílek K (2016) Redoxand non-redox-metal-induced formation of free radicals and their role in human disease. Arch Toxicol 90(1):1-37

Wang J, Luo C, Shan C, You Q, Lu J, Elf S, Zhou Y, Wen Y, Vinkenborg JL, Fan J, Kang H, Lin R, Han D, Xie Y, Karpus J, Chen S, Ouyang S, Luan C, Zhang N, Ding H, Merkx M, Liu H, Chen J, Jiang H, He C (2015) Inhibition of human copper trafficking by a small molecule significantly attenuates cancer cell proliferation. Nature Chemistry 7(12):968-979

Wang S, Sheng Z, Yang Z, Hu D, Long X, Feng G, Liu Y, Yuan Z, Zhang J, Zheng H, Zhang X (2019a) Activatable small-molecule photoacoustic probes that cross the blood-brain barrier for visualization of copper(ii) in mice with Alzheimer's disease. Angewandte Chemie (International ed. in English) 58(36):12415-12419

Wang X, Chen F, Zhang J, Sun J, Zhao X, Zhu Y, Wei W, Zhao J, Guo Z (2019) A ferroptosis-inducing iridium(III) complex. Science China Chemistry. https://doi.org/10.1007/s11426-0199577-3

Wegner SV, Sun F, Hernandez N, He C (2011) The tightly regulated copper window in yeast. Chem Commun 47(9):2571-2573

Wu L, Ding Q, Wang X, Li P, Fan N, Zhou Y, Tong L, Zhang W, Zhang W, Tang B (2020) Visualization of dynamic changes in labile iron(II) pools in endoplasmic reticulum stress-mediated drug-induced liver injury. Anal Chem 92(1):1245-1251

Xue X, Fang H, Chen H, Zhang C, Zhu C, Bai Y, He W, Guo Z (2016) In vivo fluorescence imaging for $\mathrm{Cu}^{2+}$ in live mice by a new NIR fluorescent sensor. Dyes and Pigments 130(116-121

Yang H, Han C, Zhu X, Liu Y, Zhang KY, Liu S, Zhao Q Li F, Huang W (2016) Upconversion luminescent chemodosimeter based on NIR organic dye for monitoring methylmercury in vivo. Adv Func Mater 26(12):1945-1953

Yang L, McRae R, Henary MM, Patel R, Lai B, Vogt S, Fahrni CJ (2005) Imaging of the intracellular topography of copper with a fluorescent sensor and by synchrotron X-ray fluorescence microscopy. Proc Natl Acad Sci USA 102(32):11179-11184 
Yang Y, Zhao Q Feng W, Li F (2013) Luminescent chemodosimeters for bioimaging. Chem Rev 113(1):192-270

Yao Z, Zhang BS, Prescher JA (2018) Advances in bioluminescence imaging: new probes from old recipes. Curr Opin Chem Biol 45:148-156

Zeng L, Miller EW, Pralle A, Isacoff EY, Chang CJ (2006) A selective turn-on fluorescent sensor for imaging copper in living cells. J Am Chem Soc 128(1):10-11

Zhang C, Liu M, Liu S, Yang H, Zhao Q Liu Z, He W (2018) Phosphorescence lifetime imaging of labile $\mathrm{Zn}^{2+}$ in mitochondria via a phosphorescent iridium(iii) complex. Inorg Chem 57(17):10625-10632

Zhang C, Liu Z, Li Y, He W, Gao X, Guo Z (2013) In vitro and in vivo imaging application of a 1,8-naphthalimide-derived $\mathrm{Zn}^{2+}$ fluorescent sensor with nuclear envelope penetrability. Chem Commun 49(97):11430-11432

Zhang S, Chen T-H, Lee H-M, Bi J, Ghosh A, Fang M, Qian Z, Xie F, Ainsley J, Christov C, Luo F-T, Zhao F, Liu H (2017) Luminescent probes for sensitive detection of $\mathrm{pH}$ changes in live cells through two near-infrared luminescence channels. ACS Sensors 2(7):924-931

Zhang X, Chen Y, Cai X, Liu C, Jia P, Li Z, Zhu H, Yu Y, Wang K, Li X, Sheng W, Zhu B (2020) A highly sensitive rapid-response fluorescent probe for specifically tracking endogenous labile $\mathrm{Fe}^{2+}$ in living cells and zebrafish. Dyes Pigm 174:108065

Zheng D, Feeney G, Kille P, Hogstrand C (2008) Regulation of ZIP and $\mathrm{ZnT}$ zinc transporters in zebrafish gill: zinc repression of ZIP10 transcription by an intronic MRE cluster. Physiol Genomics 34:205-214

Zhou B, Zhang J-Y, Liu X-S, Chen H-Z, Ai Y-L, Cheng K, Sun R-Y, Zhou D, Han J, Wu Q (2018) Tom20 senses iron-activated ROS signaling to promote melanoma cell pyroptosis. Cell Res 28(12):1171-1185

Zhou L, Zhang X, Wang Q Lv Y, Mao G, Luo A, Wu Y, Wu Y, Zhang J, Tan W (2014) Molecular engineering of a tbet-based twophoton fluorescent probe for ratiometric imaging of living cells and tissues. J Am Chem Soc 136(28):9838-9841

Zhu C, Wang M, Qiu L, Hao S, Li K, Guo Z, He W (2018) A mitochondria-targeting fluorescent $\mathrm{Fe}^{3+}$ probe and its application in labile $\mathrm{Fe}^{3+}$ monitoring via imaging and flow cytometry. Dyes Pigm 157:328-333

Zhu H, Fan J, Du J, Peng X (2016) Fluorescent probes for sensing and imaging within specific cellular organelles. Acc Chem Res 49(10):2115-2126 